\title{
Bimetallic Nanoparticles in Alternative Solvents for Catalytic Purposes
}

\author{
Trung Dang-Bao ${ }^{1,2}$, Daniel Pla ${ }^{1,2}$ (D), Isabelle Favier ${ }^{1,2}$ and Montserrat Gómez ${ }^{1,2 * *}$ (i) \\ 1 Laboratoire Hétérochimie Fondamentale et Appliquée (LHFA), Université de Toulouse 3-Paul Sabatier, \\ 118 route de Narbonne, 31062 Toulouse, France; dang-bao@chimie.ups-tlse.fr (T.D.-B.); \\ pla@chimie.ups-tlse.fr (D.P.); favier@chimie.ups-tlse.fr (I.F.) \\ 2 CNRS, LHFA, UMR 5069, 31062 Toulouse, France \\ * Correspondence: gomez@chimie.ups-tlse.fr; Tel.: +33-561-557-738
}

Received: 24 June 2017; Accepted: 5 July 2017; Published: 7 July 2017

\begin{abstract}
Bimetallic nanoparticles represent attractive catalytic systems thanks to the synergy between both partners at the atomic level, mainly induced by electronic effects which in turn are associated with the corresponding structures (alloy, core-shell, hetero-dimer). This type of engineered material can trigger changes in the kinetics of catalyzed processes by variations on the electrophilicity/nucleophilicity of the metal centers involved and also promote cooperative effects to foster organic transformations, including multi-component and multi-step processes. Solvents become a crucial factor in the conception of catalytic processes, not only due to their environmental impact, but also because they can preserve the bimetallic structure during the catalytic reaction and therefore increase the catalyst life-time. In this frame, the present review focuses on the recent works described in the literature concerning the synthesis of bimetallic nanoparticles in non-conventional solvents, i.e., other than common volatile compounds, for catalytic applications.
\end{abstract}

Keywords: bimetallic nanoparticles; alternative media; synthesis; structure; catalysis; water; alcohols; ionic liquids; supercritical fluids

\section{Introduction}

Transition-metal-based nanoparticles (NPs) represent unique entities for applications in catalysis due to their intrinsically electronic properties, besides the high specific surface area, in comparison to conventional heterogeneous catalysts [1]. The foremost concern is the aggregation of NPs leading to major changes in their physical properties and structure that may preclude the peculiar reactivity profiles arising from their distinct nanoscale state. Commonly, the immobilization of NPs on solid supports permits their stabilization [2-4], such as inorganic oxides [5] or carbon-based supports [6], in addition to favoring nanocatalyst recycling. In particular, bimetallic nanoparticles (BMNPs) differ from their corresponding monometallic structures in terms of morphology, composition, and structure, inducing distinctive physical and chemical properties [7]. The synergy between both metal partners, modulated by the different BMNP structural arrangements, introduces a wide diversity in reactivity, mainly due to the electronic tuning of metals [8,9].

This review focuses on BMNPs prepared in non-usual solvents which can play, together with stabilizers or capping agents, a key role in dispersion and therefore trigger a substantial impact on catalytic properties [10-12]. For each type of medium, we highlight the synthetic methodologies, mainly the wet chemical procedures such as the co-reduction of starting precursors and seeded ways, but also the sputtering physical approaches, with the final goal of correlating the main structural architectures (heterodimers, core-shell, and alloy/intermetallic arrangements) with reactivity (Figure 1) [13-15]. The efficient design of BMNPs in non-usual media can lead to sustainable methodologies for the synthesis 
of nanocatalysts, also permitting their immobilization and thus their recycling [16,17]. Concerning the design of appropriate BMNP-based catalysts, the deep impact in discriminating catalytic activity and selectivity arising from different multi-metallic systems, namely disordered alloys and ordered phases in nanomaterials, has great potential for future developments in catalysis, where control over the level of atomic precision is necessary. The differential activity of various Au-Cu BMNPs towards electrocatalytic activity for $\mathrm{CO}_{2}$ reduction or hydrogen evolution has recently been described by Yang et al. [18].

(a)

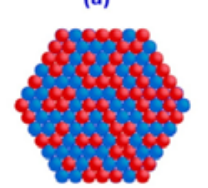

(b)

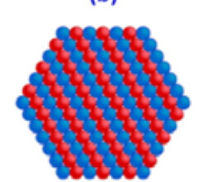

(c)

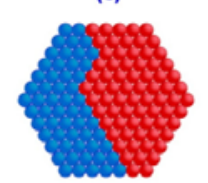

(d)

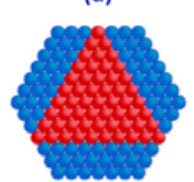

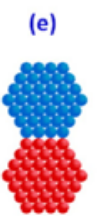
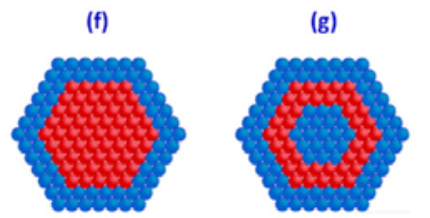

(h)

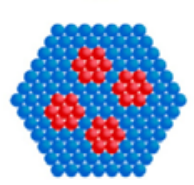

(i)

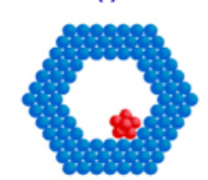

Figure 1. Structures of bimetallic nanoparticles: (a) mixed alloys; (b) alloys; (c) subclusters with two interfaces; (d) subclusters with three interfaces; (e) subclusters with a small number of A-B bonds; (f) core-shell nanoparticles; (g) multishell core-shell nanoparticles; (h) multiple small core material coated by single shell material, (i) movable core within hollow shell material. Reprinted with permission from reference [11]; license number 4133680875589. Copyright 2015, Elsevier B.V.

\section{Water}

Water represents the solvent of choice in the development of sustainable methodologies for the synthesis of metal nanoparticles, provided that reagents (metal precursors, capping agents, reducing agents) show a convenient solubility in this medium, and ruling out both the agglomeration of nanoclusters and surface state modification such as uncontrolled oxidations [19,20]; phase transfer methodologies, i.e., the transfer of metal NPs from the aqueous phase to the organic one, stand for an interesting approach which avoids the use of expensive organometallic precursors [21]. Thereafter, we describe the contributions related to the synthesis of BMNPs exhibiting applications in catalysis, both colloidal suspensions and solid-supported nanomaterials. For a summary of BMNPs in water applied in catalysis, see Table 1 at the end of this section.

\subsection{Unsupported BMNPs in Water}

Unsupported bimetallic nanoparticles in water are generally synthesized using strong reducing agents such as borohydride salts, hydrazine, hydrogen, etc. According to this strategy, Ni-Pd alloy BMNPs were prepared by the co-reduction of the metallic salts of $\mathrm{NiCl}_{2} \cdot 6 \mathrm{H}_{2} \mathrm{O}$ and $\mathrm{K}_{2}\left[\mathrm{PdCl}_{4}\right]$, using $\mathrm{NaBH}_{4}$ in the presence of polyvinylpyrrolidone (PVP) as a stabilizer in water at room temperature [22-24]. The size of the as-prepared BMNPs was in the range of $2-4 \mathrm{~nm}$ for $\mathrm{Ni}_{0.9} \mathrm{Pd}_{0.1}$, and ca. $10 \mathrm{~nm}$ for $\mathrm{Ni}_{0.99} \mathrm{Pd}_{0.01}$ and $\mathrm{Ni}_{0.95} \mathrm{Pd}_{0.05}$, exhibiting an alloy structure, as proven by TEM (Transmission Electron Microscopy), EDX (Energy-dispersive X-ray spectroscopy), and elemental mapping. The powder XRD (X-ray Diffraction) showed the planes corresponding to the face-centered cubic structure of $\mathrm{Ni}(0)$ for both materials, $\mathrm{Ni}_{0.99} \mathrm{Pd}_{0.01}$ and $\mathrm{Ni}_{0.95} \mathrm{Pd}_{0.05}$. In comparison to pure $\mathrm{Ni}$ $(3.524 \AA)$ and $\mathrm{Pd}(3.873 \AA)$, the slight change of the lattice constants in relation to $\mathrm{Ni}(0)$ for $\mathrm{Ni}_{0.99} \mathrm{Pd}_{0.01}$ $(3.527 \AA)$ and $\mathrm{Ni}_{0.95} \mathrm{Pd}_{0.05}(3.6006 \AA)$ confirmed the formation of an alloy displaying a lattice expansion from the substitution of $\mathrm{Ni}$ by Pd atoms in this frame. More significantly, XPS spectra for the Pd $3 \mathrm{~d}_{5 / 2}$ and $\mathrm{Ni} 2 \mathrm{p}_{3 / 2}$ exhibited significant shifts in binding energies $\left(\Delta \mathrm{E}\right.$ for $\mathrm{Ni} 2 \mathrm{p}_{3 / 2}$ are 0 and $+0.2 \mathrm{eV}, \Delta \mathrm{E}$ for $\mathrm{Pd} 3 \mathrm{~d}_{5 / 2}$ are +0.5 and $+0.6 \mathrm{eV}$ for $\mathrm{Ni}_{0.99} \mathrm{Pd}_{0.01}$ and $\mathrm{Ni}_{0.95} \mathrm{Pd}_{0.05}$ compared to the pure monometallic 
counterparts, respectively) [20]. The very low content of Pd in these alloys results in a significant positive shift for the $\mathrm{Pd} 3 \mathrm{~d}_{5 / 2}$ binding energy, due to not only a charge transfer effect, but more plausibly, to lattice structural modification $[25,26]$. Singh's group applied these BMNPs as catalysts for C-C coupling reactions using a mixture of $\mathrm{H}_{2} \mathrm{O}: \mathrm{C}_{2} \mathrm{H}_{5} \mathrm{OH}(1: 1 v / v)$ as the solvent for Suzuki-Miyaura cross-coupling, and $\mathrm{H}_{2} \mathrm{O}: \mathrm{DMF}(1: 1 v / v)$ as the solvent for Heck and Sonogashira reactions, obtaining the corresponding coupling products in a moderate to high yield [22,24]. High $\mathrm{Ni}$ to $\mathrm{Pd}$ ratios in such BMNPs improved both the catalytic activity and stability of the catalyst, showing $>90 \%$ conversion even after the seventh run (using $\mathrm{Ni}_{0.95} \mathrm{Pd}_{0.05}$ as the catalyst for the Suzuki-Miyaura reaction between 4-iodoanisole and 2-methylphenylboronic acid at room temperature). This behavior can be explained by the synergistic effect between both metals, as the charge transfer from $\mathrm{Ni}$ to $\mathrm{Pd}$ atoms resulting in Pd electron-enriched centers, favoring the oxidative addition elementary step of aryl halides and hence improving the reactivity of NiPd BMNPs [22,24] (Figure 2). Singh and coworkers also reported the one-pot direct transformation of furfuryl alcohol to 2-furoic acid in water under continuous air bubbling at $80{ }^{\circ} \mathrm{C}$ for $4 \mathrm{~h}$, using $5 \mathrm{~mol} \%$ of $\mathrm{Ni}_{0.90} \mathrm{Pd}_{0.10}$ alloy as the catalyst, showing full conversion with $>99 \%$ selectivity [23].
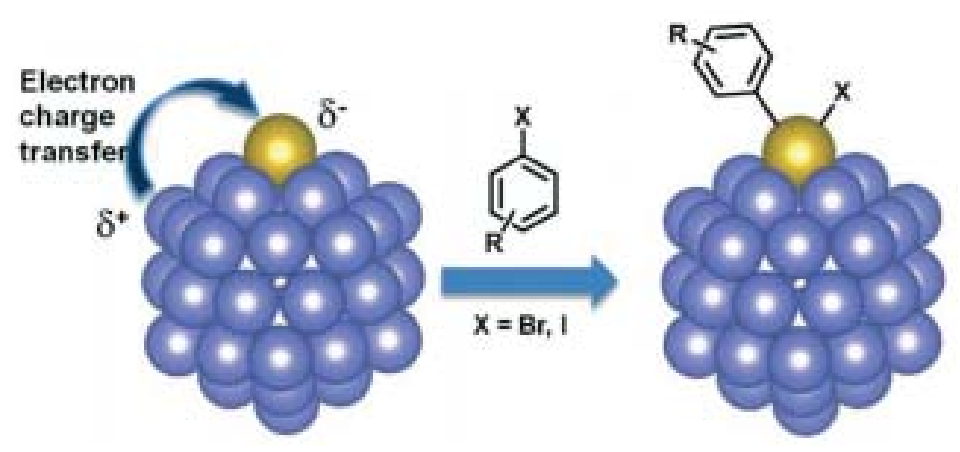

Figure 2. Electronic transfer from $\mathrm{Ni}$ (blue) to Pd (yellow) and the oxidative addition of aryl halides on Pd atoms. Reproduced from reference [24] with permission of The Royal Society of Chemistry.

Zhang et al., reported the synthesis of NiFe BMNPs in water using $\mathrm{NaBH}_{4}$ as a reductant and their application in the catalytic dechlorination of polychlorinated biphenyls under subcritical water conditions [27]. Cervantes and co-workers also reported bimetallic $\mathrm{PdCu}$ alloys synthesized from aqueous solutions of $\mathrm{H}_{2}\left[\mathrm{PdCl}_{4}\right]$ and $\mathrm{H}_{2}\left[\mathrm{CuCl}_{4}\right]$ with additives such as PVP, L-ascorbic acid, and citric acid towards the catalytic reduction of $p$-nitrophenol [28].

Furthermore, spherical $\mathrm{Pd}_{0.5} \mathrm{Ni}_{0.5}, \mathrm{Pd}_{0.5} \mathrm{Cu}_{0.5}, \mathrm{Pd}_{4} \mathrm{Cu}_{1}$, and $\mathrm{Pd}_{0.5} \mathrm{Ag}_{0.5}$ alloys were also prepared by the co-reduction of $\mathrm{Pd}(\mathrm{OAc})_{2}$ and the corresponding nickel, copper, or silver salt $\left(\mathrm{NiSO}_{4} \cdot 6 \mathrm{H}_{2} \mathrm{O}\right.$, $\mathrm{CuSO}_{4} \cdot 5 \mathrm{H}_{2} \mathrm{O}$ or $\left.\mathrm{Cu}(\mathrm{OAc})_{2}, \mathrm{AgNO}_{3}\right)$, using hydrazine as the reducing agent in a water-in-oil microemulsion system constituted by water/dioctyl sulfosuccinate sodium salt/isooctane at ambient conditions $[29,30]$. The resulting BMNPs were analyzed by TEM, showing a mean diameter in the range of $6-20 \mathrm{~nm}$. The structure and elemental composition were determined by XRD, XRF (X-ray Fluorescence), and EDX analyses. Compared to monometallic NPs, $\mathrm{Pd}_{0.5} \mathrm{Ni}_{0.5} \mathrm{BMNPs}$ revealed the highest activity for the Buchwald-Hartwig aminations of aryl chlorides, using water as the solvent at $80{ }^{\circ} \mathrm{C}$; high yields $(86-100 \%)$ were obtained together with an efficient catalytic recycling (up to seven consecutive runs). As stated above, the presence of $\mathrm{Ni}$ leads to electron-rich $\mathrm{Pd}$ centers favoring the $\mathrm{C}-\mathrm{Cl}$ bond activation in the oxidative addition step; the regeneration of $\mathrm{Pd}(0)$ is promoted by the electron transfer process between both metals $\left(\mathrm{Ni}^{\circ}+\mathrm{Pd}^{2+} \rightarrow \mathrm{Ni}^{2+}+\mathrm{Pd}^{\circ}\right)$ (Figure 3) [30]. 


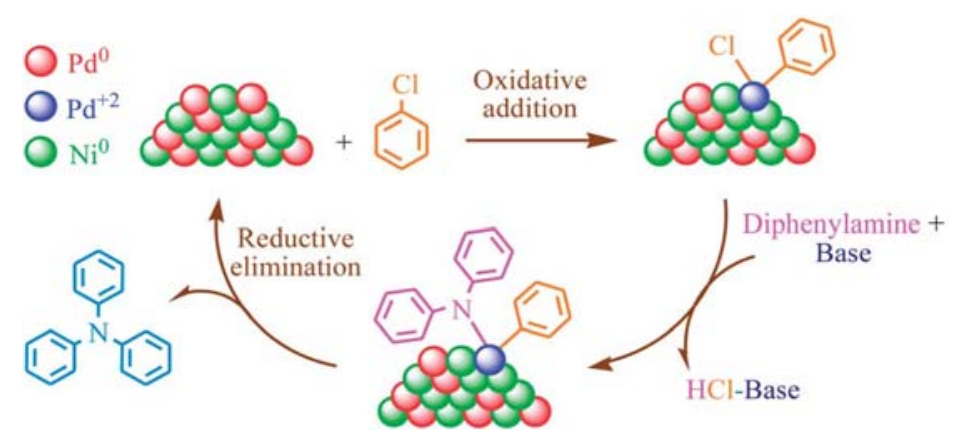

Figure 3. Catalytic pathway of the amination reaction on the surface of $\mathrm{Pd}_{0.5} \mathrm{Ni}_{0.5}$ BMNPs. Reproduced from reference [30] with permission of The Royal Society of Chemistry.

Sharma and co-workers reported the synthesis of small spherical PtCu alloys ( $3 \mathrm{~nm}$ ) in water-in-oil microemulsions of water/sodium dioctylsulfosuccinate/hexane by the reduction of the corresponding salts $\left(\mathrm{H}_{2}\left[\mathrm{PtCl}_{6}\right]\right.$ and $\left.\mathrm{Cu}(\mathrm{OAc})_{2}\right)$, using hydrazine hydrate as the reducing agent at $5{ }^{\circ} \mathrm{C}[31]$.

The green synthesis of BMNPs using plants as reducing agents has been recently studied. Thus, Philip et al. prepared Au-Ag BMNPs by the simultaneous reduction of $\mathrm{H}\left[\mathrm{AuCl}_{4}\right]$ and $\mathrm{AgNO}_{3}$ in water, in the presence of pomegranate fruit juice. Different molar ratios of metal ions led to the formation of alloy (for $\mathrm{Au} / \mathrm{Ag}=1: 5 ; 1: 4 ; 1: 3 ; 1: 2$ ) or core-shell nanostructures (for $\mathrm{Au} / \mathrm{Ag}=1: 1$ ). These catalysts were applied in the reduction of 2-, 3-, and 4-nitrophenol to the corresponding anilines and also in the degradation of methyl orange in water [32]. Nasrollahzadeh's group used Euphorbia condylocarpa M. bieb root extract as both the reducing agent and stabilizer to synthesize AuPd BMNPs from $\mathrm{H}\left[\mathrm{AuCl}_{4}\right]$ and $\mathrm{PdCl}_{2}$ in water. The as-prepared BMNPs were characterized by powder XRD, SEM (Scanning Electron Microscopy), and EDX, and were then used as reusable catalysts for Suzuki and Heck C-C cross-coupling reactions in water, maintaining the catalytic activity up to the fourth run [33].

Seeded growth synthetic methodologies have been developed in the literature. Fe-Pd BMNPs were synthesized by soaking freshly preformed iron nanoparticles [34], both in an ethanol solution of $\mathrm{Pd}(\mathrm{OAc})_{2}$ [35] and in an aqueous solution of $\mathrm{K}_{2}\left[\mathrm{PdCl}_{6}\right]$ [36], resulting in the reduction of $\mathrm{Pd}(\mathrm{II})$ into $\mathrm{Pd}(0)$ and its subsequent deposition on the Fe surface $\left(\mathrm{Fe}^{\circ}+\mathrm{Pd}^{2+} \rightarrow \mathrm{Fe}^{2+}+\mathrm{Pd}^{\circ}\right)$. The obtained spherical nanoparticles of $25-40 \mathrm{~nm}$ in diameter were connected in chains of beads, thanks to the magnetic and electronic interactions between both metals. The use of an excess of reducing agent favors a rapid and uniform growth of iron nanocrystals. XPS analyses indicated the presence of $\mathrm{Fe}(0), \mathrm{Fe}(\mathrm{II})$, and $\mathrm{Pd}(0)$, whilst XRD showed the existence of only crystalline bcc $\mathrm{Fe}(0)$. No data is reported concerning the structure of the as-prepared BMNPs. Fe-Pd BMNPs were active for the full dechlorination of $\gamma$-hexachlorocyclohexane in aqueous solution at $25^{\circ} \mathrm{C}$, yielding cyclohexane as a single product. From a mechanistic point of view, hydrogen was generated via Fe corrosion in water and then dissociated to form the metal-hydride on the Pd surface (or $\mathrm{H} \bullet$ radicals). The labilization of the $\mathrm{C}$ - $\mathrm{Cl}$ bond of $\gamma$-hexachlorocyclohexane due to adsorption on the surface of the nanoparticles leads to the replacement of chlorine atoms by the active metal-hydride (or $\mathrm{H} \bullet$ radicals) to furnish cyclohexane $[35,37]$. Following a similar strategy, $\mathrm{Xu}$ et al. prepared FeNi BMNPs by a reaction between preformed monometallic $\mathrm{Fe}(0) \mathrm{NPs}$ and $\mathrm{NiSO}_{4} \cdot 6 \mathrm{H}_{2} \mathrm{O}$ in water [38]. This catalyst was used for the dechlorination of Aroclor 1242 (polychlorinated biphenyl), reaching nearly $96 \%$ of the dehalogenated product at $25^{\circ} \mathrm{C}$ after $10 \mathrm{~h}$ of reaction.

Sequential reduction is considered as one of the most suitable methods to prepare core-shell BMNPs. Fu's group reported the synthesis of core-shell AuPd BMNPs in water [39]. Firstly, AuNPs in colloidal solution were formed by the reduction of $\mathrm{H}\left[\mathrm{AuCl}_{4}\right]$ with an aqueous solution of sodium citrate, tannic acid, and potassium carbonate at $120^{\circ} \mathrm{C}$. After centrifugation and washing with water, the resulting powder was re-dispersed in ultrapure water yielding a brown-red colloidal solution of monometallic AuNPs, which was then treated with an aqueous solution of $\mathrm{H}_{2}\left[\mathrm{PdCl}_{4}\right]$ under $\mathrm{H}_{2}$ 
bubbling for at least $3 \mathrm{~min}$, affording a brown solution of AuPd BMNPs (Au/Pd mass ratio $=1 / 1)$. SEM and HR-TEM analyses of the as-prepared BMNPs showed the face centered cubic structure of spherical particles with a mean size of ca. $8 \mathrm{~nm}$, exhibiting a bigger size than the corresponding monometallic nanoparticles (ca. $5 \mathrm{~nm}$ for both monometallic AuNPs and PdNPs). The line scanning analysis in the STEM-EDX method of an individual AuPd nanoparticle indicated the lightly broader signal of $\mathrm{Pd}$ corresponding to the formation of the prominent structure of the Pd-shell, compared to that of the Au-core [40]. These core-shell BMNPs were active catalysts for the dechlorination of diclofenac in water under $\mathrm{H}_{2}$ atmosphere at room temperature (full conversion, $\mathrm{pH}=7,4.5 \mathrm{~h}$ of reaction) (Scheme 1 ).

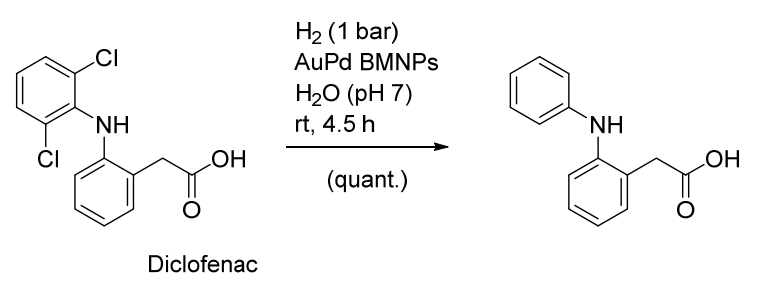

Scheme 1. Dechlorination of diclofenac under hydrogen atmosphere catalyzed by AuPd BMNPs [39].

Scott and co-workers described the preparation of PVP-AuPd (1:3) BMNPs using a similar sequential reduction method. PVP-stabilized monometallic AuNPs from an aqueous solution of $\mathrm{HAuCl}_{4}$ were pre-formed using $\mathrm{NaBH}_{4}$ as the reductant. Then, the mixing of gold seed nanoparticles and $\mathrm{K}_{2}\left[\mathrm{PdCl}_{4}\right]$ in water was treated by ascorbic acid, leading to the formation of core-shell structural BMNPs [41,42]. The mean size of these BMNPs was ca. $4.2 \mathrm{~nm}$, being bigger than the corresponding monometallic AuNPs $(2.8 \mathrm{~nm})$. Structural elucidation was established by EXAFS, evidencing a Pd-enriched surface and a gold core. In addition, the XANES spectra of Pd-LIII edges evidenced significant d-charge depletion in relation to monometallic PdNPs and alloy AuPd BMNPs. This as-prepared catalyst was applied in the selective aerobic oxidation of aliphatic and aromatic unsaturated alcohol towards the corresponding aldehydes or ketones under smooth conditions in water, in the absence of a base and using molecular oxygen as the oxidant.

\subsection{Supported BMNPs in Water}

Inorganic oxides and carbon-based supports generally facilitate the immobilization of metallic nanoparticles by impregnation, as well as their separation after the reaction and then their recycling. $\mathrm{Li}$ and co-workers synthesized $\mathrm{CuPd}$ BMNPs supported on $\gamma-\mathrm{Al}_{2} \mathrm{O}_{3}$ by the impregnation of $\mathrm{Cu}\left(\mathrm{NO}_{3}\right)_{2}$ and $\mathrm{H}_{2}\left[\mathrm{PdCl}_{4}\right]$ [43]. Aqueous solutions of $\mathrm{H}_{2}\left[\mathrm{PdCl}_{4}\right]$ and $\mathrm{Cu}\left(\mathrm{NO}_{3}\right)_{2}$ were successively added dropwise into the solution containing $\gamma-\mathrm{Al}_{2} \mathrm{O}_{3}$ in distilled water under vigorous stirring at $80{ }^{\circ} \mathrm{C}$ for $5 \mathrm{~h}$. Then, the $\mathrm{pH}$ value was adjusted to $8-9$ by the addition of an aqueous $\mathrm{NaHCO}_{3}$ solution. The resulting solid was filtered, washed with distilled water, dried under vacuum at $383 \mathrm{~K}$, calcined at $533 \mathrm{~K}$ for $3 \mathrm{~h}$, and finally treated with $\mathrm{H}_{2}$ at $533 \mathrm{~K}$. The as-prepared supported metal nanoparticles $(6.9 \mathrm{~nm}$ of mean diameter) were highly dispersed on $\gamma-\mathrm{Al}_{2} \mathrm{O}_{3}$. The specific surface area of CuPd BMNPs $/ \gamma-\mathrm{Al}_{2} \mathrm{O}_{3}$ was slightly increased, but the total pore volume and mean pore size decreased, in comparison to $\gamma-\mathrm{Al}_{2} \mathrm{O}_{3}$. Besides CuPd BMNPs, monometallic PdNPs could also be observed on the surface of the $\gamma-\mathrm{Al}_{2} \mathrm{O}_{3}$ support to a minor extent. These supported BMNPs were active for the transfer hydrogenation of nitrobenzene derivatives and sequential cyclization coupling using o-nitroaniline and alcohols to afford benzimidazoles (up to a $98.2 \%$ yield using $5 \mathrm{~mol} \%$ loading for each metal, under $3.5 \mathrm{MPa}$ of $\mathrm{N}_{2}$ at $453 \mathrm{~K}$ for $12 \mathrm{~h}$ ) (Figure 4 ). However, no conversion was observed using $\mathrm{CuNPs} / \gamma-\mathrm{Al}_{2} \mathrm{O}_{3}$, and only a $6.5 \%$ conversion was recorded when using PdNPs $/ \gamma-\mathrm{Al}_{2} \mathrm{O}_{3}$. Notably, the cooperative effects of $\mathrm{CuPd}$ NPs could be evidenced when the palladium content of the catalyst increased as the activity rapidly increased: from a $21.9 \%$ yield for $\mathrm{Cu}_{5} \mathrm{Pd}_{1} / \gamma-\mathrm{Al}_{2} \mathrm{O}_{3}$ to a $95.4 \%$ yield for $\mathrm{Cu}_{5} \mathrm{Pd}_{10} / \gamma-\mathrm{Al}_{2} \mathrm{O}_{3}$. 


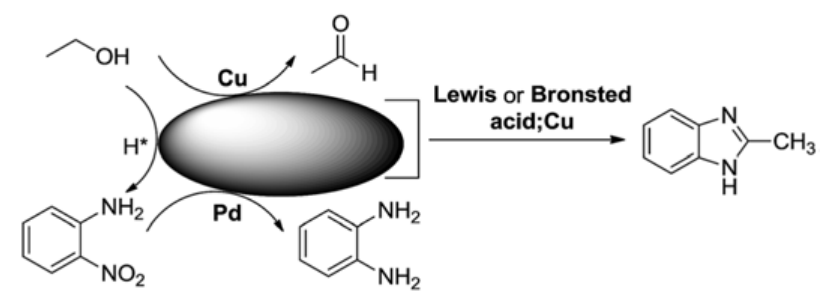

Figure 4. Synthesis of 2-methyl benzimidazole from ethanol and o-nitroaniline catalyzed by a multifunctional CuPd NPs $/ \gamma-\mathrm{Al}_{2} \mathrm{O}_{3}$. Reproduced from reference [43] with permission of The Royal Society of Chemistry.

Furthermore, one can envisage the concomitant synthesis of both BMNPs and the solid support, such as silica, by in situ methodologies from metal salts and organosilicates. As a highly valuable and sophisticated impregnation method, Zhang et al. reported the synthesis of $\mathrm{CuNi}_{\mathrm{SiO}}$ from the reverse-microemulsion of $\mathrm{Cu}\left(\mathrm{NO}_{3}\right)_{2} \cdot 3 \mathrm{H}_{2} \mathrm{O}$ and $\mathrm{Ni}\left(\mathrm{NO}_{3}\right)_{2} \cdot 6 \mathrm{H}_{2} \mathrm{O}$ in a mixture of Brij ${ }^{\circledR} 58$ (polyethylene glycol hexadecyl ether) and cyclohexane, followed by aqueous ammonia treatment and tetraethyl orthosilicate (TEOS) hydrolysis at the oil/water interface to trigger the formation of a 3-D network structure $\mathrm{Cu}(\mathrm{II}) / \mathrm{Ni}(\mathrm{II}) @ \mathrm{SiO}_{2}$ [44]. After drying, $\mathrm{Cu}(\mathrm{OH})_{2} / \mathrm{Ni}(\mathrm{OH})_{2} @ \mathrm{SiO}_{2}$ was generated, followed by $\mathrm{CuO} / \mathrm{NiO} @ \mathrm{SiO}_{2}$ after calcination at $500{ }^{\circ} \mathrm{C}$. Finally, $\mathrm{CuO}$ and $\mathrm{NiO}$ were reduced to $\mathrm{CuNi@SiO}{ }_{2}$ under $\mathrm{H}_{2}$ atmosphere at a high temperature $\left(350^{\circ} \mathrm{C}\right)$ [44]. The size and composition of these as-prepared BMNPs were characterized by FT-IR (Fast Transform-InfraRed spectroscopy), TEM, XPS, XRD, and ICP-OES (Inductively Coupled Plasma Optical Emission Spectrometry) [44]. As a catalyst for the reduction of $p$-nitrophenol in water by $\mathrm{NaBH}_{4}$, the calculated activation energy of $\mathrm{Cu}_{54} \mathrm{Ni}_{46} @ \mathrm{SiO}_{2}$ (CuNi BMNPs showed a mean size of $5.7 \mathrm{~nm}$ ) was much lower $(16.6 \mathrm{~kJ} / \mathrm{mol})$ than that of monometallic $\mathrm{Cu} @ \mathrm{SiO}_{2}(29.0 \mathrm{~kJ} / \mathrm{mol})$ and $\mathrm{Ni} @ S i O_{2}(39.5 \mathrm{~kJ} / \mathrm{mol})$. This $\mathrm{CuNi}_{\mathrm{SiO}}$ nanocatalyst was recycled up to 10 times whilst preserving its reactivity ( $>90 \%$ conversion for 10th run).

Fe-Ni BMNPs supported on montmorillonite (MMT, soft phyllosilicate mineral) have recently been developed by Chikate and coworkers [45]. Thus, an aqueous solution of $\mathrm{FeSO}_{4} \cdot 7 \mathrm{H}_{2} \mathrm{O}$ and $\mathrm{NiSO}_{4} \cdot 6 \mathrm{H}_{2} \mathrm{O}$ was mixed with a suspension of $\mathrm{Na}^{+}-\mathrm{MMT}$ in deionized water, before being reduced by the dropwise addition of $\mathrm{NaBH}_{4}$ under $\mathrm{N}_{2}$ atmosphere. The as-prepared composites were characterized by XRD, TEM, and $\mathrm{NH}_{3}$-TPD (Temperature Programmed Desorption) and were then applied as catalysts for the reductive cyclization of levulinic acid (LA) to $\gamma$-valerolactone (GLV). The reduction of LA took place on the bimetallic sites, while the subsequent cyclization to GLV was favored on the strong acidic sites of MMT. Despite the high reactivity (conversion of $90 \%$ after $1 \mathrm{~h}$ ), substantial leaching of iron was observed when using water as the solvent.

Another example of a co-reduction methodology by Yamauchid et al. yielded AuPd alloys supported on graphene oxide (GO) nanosheets by the treatment of a GO water suspension with an aqueous solution of $\mathrm{H}\left[\mathrm{AuCl}_{4}\right]$ and $\mathrm{PdCl}_{2}$, using ascorbic acid as the reducing agent [46]. The resulting material was employed as an efficient photocatalyst for the degradation of phenolic compounds in water and it could be recycled up to five times. Long et al. reported the preparation of FePd BMNPs supported on chelating resin from $\mathrm{Fe}_{2}\left(\mathrm{SO}_{4}\right)_{3}$ and $\mathrm{PdCl}_{2}$ using $\mathrm{NaBH}_{4}$ as the reducing agent in water; these catalysts were used for the selective reduction of nitrate into nitrogen [47].

Similar to the synthesis of colloidal BMNPs, supported core-shell structure BMNPs were obtained following a sequential procedure. Ag-core@Pt-shell BMNPs supported on sepiolite (soft clay mineral) nanofibers were reported by Zhang and co-workers [48]. $\mathrm{AgNO}_{3}$ and $\mathrm{H}_{2}\left[\mathrm{PtCl}_{6}\right] \cdot 6 \mathrm{H}_{2} \mathrm{O}$ were successively reduced using ascorbic acid and PVP, which acts both as the stabilizer and dispersing agent. The silver cores coated with platinum shells were obtained as a colloidal solution and were then mixed with a suspension of sepiolite nanofibers in water. The resulting material exhibited Ag-core@Pt-shell NPs with a mean size of 30-50 nm and a spherical or elliptical shape, well-dispersed on the sepiolite nanofiber, as evidenced by TEM, HR-TEM, XRD, XPS, and FT-IR techniques. This 
catalyst enhanced the catalytic performance for the reduction of nitrophenols in water, thanks to its large surface area, high porosity, and unique electronic structure (charge redistribution and s-d hybridization between Ag cores and Pt shells), in comparison with the corresponding monometallic counterparts on sepiolite; it was recycled up to five runs.

Following a similar sequential chemical reduction, Fu's group prepared core-shell Au-Pd BMNPs from preformed monometallic AuNPs in water (using sodium citrate as the reductant in a mixture of tannic acid and potassium carbonate), which were treated with $\mathrm{H}_{2}\left[\mathrm{PdCl}_{4}\right]$ under $\mathrm{H}_{2}$ pressure [49]. Finally, Au-Pd BMNPs were supported on amberlite 717 (tradename of ion-exchange resins) by soaking. The as-prepared catalytic material was applied to the complete transformation of chloramphenicol to $\mathrm{N}$-(1,3-dihydroxyl-1-(4-nitrophenyl)propan-2-yl)acetamide in water under $\mathrm{H}_{2}$ atmosphere at room temperature in $3 \mathrm{~h}$; the catalyst was reused five consecutive times [49].

Moreover, bimetallic Au-Pt NPs on zeolites could also be synthesized by a sequential deposition protocol [50]. First, monometallic AuNPs on zeolite were obtained by the $\mathrm{NaBH}_{4}$ reduction of $\mathrm{H}\left[\mathrm{AuCl}_{4}\right]$ in a water solution containing polyvinyl alcohol (PVA) as an additive. Treatment of the as-prepared monometallic nanocomposites with an aqueous solution of $\mathrm{K}_{2}\left[\mathrm{PtCl}_{4}\right]$ and PVA under atmospheric pressure of $\mathrm{H}_{2}$ gas ( $9.86 \mathrm{vol} \%$ in $\mathrm{N}_{2}$, flow rate of $150 \mathrm{~mL} / \mathrm{min}$ ) and room temperature for $6 \mathrm{~h}$, permitted the researchers to obtain highly dispersed BMNPs on zeolites, exhibiting a mean diameter of 4-4.5 nm. These catalysts were applied to the conversion of glycerol into lactic acid or glyceric acid in water under base-free conditions [50]. Similarly, carbon supported BMNPs showing an internal core of $\mathrm{Cu}$ atoms and an outer shell of $\mathrm{Pt}$ atoms were synthesized from $\mathrm{Cu}(\mathrm{II})$ and $\mathrm{Pt}(\mathrm{IV})$ metal precursors in a dispersion of carbon (Vulcan XC72, Cabot) in an ethylene glycol/water mixture as the solvent, for applications as electrocatalysts [51].

Table 1. Bimetallic nanoparticles in water applied in catalysis. ${ }^{a}$

\begin{tabular}{|c|c|c|c|c|c|c|}
\hline Entry & $\begin{array}{c}\text { BMNPs } \\
\text { (Mean Size, nm) }\end{array}$ & Structure $^{a}$ & Metallic Precursors & $\begin{array}{l}\text { Synthetic } \\
\text { Procedure }\end{array}$ & Catalytic Reaction & Refs. \\
\hline 1 & $\mathrm{NiPd}(2-4)$ & alloys & $\begin{array}{c}\mathrm{NiCl}_{2} \cdot 6 \mathrm{H}_{2} \mathrm{O}, \\
\mathrm{K}_{2}\left[\mathrm{PdCl}_{4}\right]\end{array}$ & co-reduction & C-C cross-couplings & [22-24] \\
\hline 2 & NiFe (10-70) & n.r. & $\begin{array}{c}\mathrm{FeSO}_{4} \cdot 7 \mathrm{H}_{2} \mathrm{O} \\
\mathrm{Ni}\left(\mathrm{NO}_{3}\right)_{2} \cdot 6 \mathrm{H}_{2} \mathrm{O}\end{array}$ & co-reduction & dechlorinations & [27] \\
\hline 3 & $\mathrm{PdCu}(3-7)$ & alloys & $\begin{array}{l}\mathrm{H}_{2}\left[\mathrm{PdCl}_{4}\right] \\
\mathrm{H}_{2}\left[\mathrm{CuCl}_{4}\right]\end{array}$ & co-reduction & $p$-nitrophenol reduction & [28] \\
\hline 4 & $\mathrm{PdNi}(6-20)$ & alloys & $\begin{array}{c}\mathrm{Pd}(\mathrm{OAc})_{2} \\
\mathrm{NiSO}_{4} \cdot 6 \mathrm{H}_{2} \mathrm{O}\end{array}$ & co-reduction & $\begin{array}{l}\text { Buchwald-Hartwig } \\
\text { aminations }\end{array}$ & [30] \\
\hline 5 & $\mathrm{PtCu}(3)$ & alloys & $\begin{array}{l}\mathrm{H}_{2}\left[\mathrm{PtCl}_{6}\right] \\
\mathrm{Cu}(\mathrm{OAc})_{2}\end{array}$ & co-reduction & $\begin{array}{c}\text { Rhodamine B } \\
\text { degradation }\end{array}$ & [31] \\
\hline 6 & $\mathrm{AuAg}(12)$ & alloys & $\mathrm{H}\left[\mathrm{AuCl}_{4}\right], \mathrm{AgNO}_{3}$ & co-reduction & nitrophenols reduction & {$[32]$} \\
\hline 7 & $\mathrm{AuAg}(8)$ & core $(\mathrm{Au})$-shell( $\mathrm{Ag})$ & $\mathrm{H}\left[\mathrm{AuCl}_{4}\right], \mathrm{AgNO}_{3}$ & co-reduction & nitrophenols reduction & [32] \\
\hline 8 & $\mathrm{AuPd}(80)$ & n.r. & $\mathrm{H}\left[\mathrm{AuCl}_{4}\right], \mathrm{PdCl}_{2}$ & co-reduction & $\begin{array}{l}\text { Suzuki and Heck C-C } \\
\text { cross-couplings }\end{array}$ & [33] \\
\hline 9 & FePd (25-40) & n.r. & $\begin{array}{c}\mathrm{Pd}(\mathrm{OAc})_{2} \\
\mathrm{FeSO}_{4} \cdot 7 \mathrm{H}_{2} \mathrm{O}\end{array}$ & $\begin{array}{c}\text { sequential } \\
\text { reduction }\end{array}$ & dechlorination & [34-36] \\
\hline 10 & FeNi (20-100) & n.r. & $\begin{array}{l}\mathrm{NiSO}_{4} \cdot 6 \mathrm{H}_{2} \mathrm{O} \\
\mathrm{FeSO}_{4} \cdot 7 \mathrm{H}_{2} \mathrm{O}\end{array}$ & $\begin{array}{l}\text { sequential } \\
\text { reduction }\end{array}$ & dechlorination & [38] \\
\hline 11 & AuPd (8) & $\operatorname{core}(\mathrm{Au})$-shell(Pd) & $\begin{array}{l}\mathrm{H}\left[\mathrm{AuCl}_{4}\right] \\
\mathrm{H}_{2}\left[\mathrm{PdCl}_{4}\right]\end{array}$ & $\begin{array}{l}\text { sequential } \\
\text { reduction }\end{array}$ & dechlorination & [39] \\
\hline 12 & $\mathrm{AuPd}(4.2)$ & core $(\mathrm{Au})$-shell( $(\mathrm{Pd})$ & $\begin{array}{l}\mathrm{H}\left[\mathrm{AuCl}_{4}\right] \\
\mathrm{K}_{2}\left[\mathrm{PdCl}_{4}\right]\end{array}$ & $\begin{array}{l}\text { sequential } \\
\text { reduction }\end{array}$ & $\begin{array}{c}\text { oxidation of } \\
\text { unsaturated alcohols }\end{array}$ & {$[41,42]$} \\
\hline 13 & $\begin{array}{c}\mathrm{CuPd} @ \gamma-\mathrm{Al}_{2} \mathrm{O}_{3} \\
(6.9)\end{array}$ & alloys & $\begin{array}{l}\mathrm{Cu}\left(\mathrm{NO}_{3}\right)_{2} \\
\mathrm{H}_{2}\left[\mathrm{PdCl}_{4}\right]\end{array}$ & co-reduction & transfer hydrogenation & [43] \\
\hline 14 & $\mathrm{CuNi@SiO} 2$ (5.7) & alloys & $\begin{array}{l}\mathrm{Cu}\left(\mathrm{NO}_{3}\right)_{2} \\
\mathrm{Ni}\left(\mathrm{NO}_{3}\right)_{2}\end{array}$ & co-reduction & $p$-nitrophenol reduction & [44] \\
\hline 15 & FeNi@MMT (30-40) & n.r. & $\begin{array}{l}\mathrm{FeSO}_{4} \cdot 7 \mathrm{H}_{2} \mathrm{O} \\
\mathrm{NiSO}_{4} \cdot 6 \mathrm{H}_{2} \mathrm{O}\end{array}$ & co-reduction & $\begin{array}{c}\text { reductive cyclization of } \\
\text { levulinic acid }\end{array}$ & [45] \\
\hline 16 & AuPd@GO (37) & alloys & $\mathrm{H}\left[\mathrm{AuCl}_{4}\right], \mathrm{PdCl}_{2}$ & co-reduction & $\begin{array}{c}\text { photocatalytic } \\
\text { degradation of phenols }\end{array}$ & [46] \\
\hline
\end{tabular}


Table 1. Cont.

\begin{tabular}{|c|c|c|c|c|c|c|}
\hline Entry & $\begin{array}{c}\text { BMNPs } \\
\text { (Mean Size, nm) }\end{array}$ & Structure $^{a}$ & Metallic Precursors & $\begin{array}{l}\text { Synthetic } \\
\text { Procedure }\end{array}$ & Catalytic Reaction & Refs. \\
\hline 17 & $\begin{array}{l}\text { FePd@DOW }^{\circledR} \\
\text { M4195 (3-5) }\end{array}$ & n.r. & $\mathrm{Fe}_{2}\left(\mathrm{SO}_{4}\right)_{3}, \mathrm{PdCl}_{2}$ & co-reduction & nitrate reduction & {$[47]$} \\
\hline 18 & $\begin{array}{c}\text { AgPt@sepiolite } \\
(30-50)\end{array}$ & core $(\mathrm{Ag})$-shell(Pt) & $\begin{array}{c}\mathrm{AgNO}_{3} \\
\mathrm{H}_{2}\left[\mathrm{PtCl}_{6}\right] \cdot 6 \mathrm{H}_{2} \mathrm{O}\end{array}$ & $\begin{array}{l}\text { sequential } \\
\text { reduction }\end{array}$ & nitrophenols reduction & [48] \\
\hline 19 & AuPd@amberlite (8) & $\operatorname{core}(\mathrm{Au})$-shell($(\mathrm{Pd})$ & $\begin{array}{l}\mathrm{H}\left[\mathrm{AuCl}_{4}\right], \\
\mathrm{H}_{2}\left[\mathrm{PdCl}_{4}\right]\end{array}$ & $\begin{array}{l}\text { sequential } \\
\text { reduction }\end{array}$ & hydrogenation & [49] \\
\hline 20 & $\begin{array}{c}\text { AuPt@zeolite } \\
(4-4.5)\end{array}$ & n.r. & $\mathrm{H}\left[\mathrm{AuCl}_{4}\right], \mathrm{K}_{2}\left[\mathrm{PtCl}_{4}\right]$ & $\begin{array}{l}\text { sequential } \\
\text { reduction }\end{array}$ & oxidation of glycerol & [50] \\
\hline 21 & CuPt@C (10-12) & $\operatorname{core}(\mathrm{Cu})$-shell(Pt) & $\mathrm{CuSO}_{4}, \mathrm{H}_{2}\left[\mathrm{PtCl}_{6}\right]$ & $\begin{array}{l}\text { sequential } \\
\text { reduction }\end{array}$ & $\begin{array}{l}\text { oxygen reduction } \\
\text { reaction }\end{array}$ & [51] \\
\hline
\end{tabular}

a For abbreviations: n.r. = not reported; $\mathrm{MMT}=$ montmorillonite; $\mathrm{GO}=$ graphene oxide; $\mathrm{DOW}{ }^{\circledR} \mathrm{M} 4195$ = weakly basic solid supported polyamine chelating anion exchange resin.

\section{Alcohols}

In contrast to water, alcohols exhibit the advantage that they can act as reducing agents of metal precursors, particularly when using polyols. Ethylene glycol and polyethylene glycol are among the most frequently applied ones towards bottom-up synthetic approaches of metal colloidal suspensions, where the polyalcohol plays a role as both the solvent and reducing agent of the metallic precursor [52]. In some cases, this methodology can affect the kinetics of the growth step and define the shape of the nanoparticles [53]. In our group, glycerol has been applied in the synthesis of metal and metal oxide nanoparticles under hydrogen atmosphere, precluding its reductant behaviour; glycerol acts as liquid support by the efficient immobilization of MNPs [54-57]. Contrary to monometallic nanoparticles, BMNPs prepared in alcohol medium are less common. For a summary of BMNPs in alcohols applied in catalysis, see Table 2 at the end of this section.

\subsection{Unsupported BMNPs in Alcohols}

Analogously to the preparation of alloy-based BMNPs in water, the reduction of two metal salts in alcohols is simultaneously undertaken in the presence of strong reducing agents. Mandal and co-workers reported the synthesis of $\mathrm{CuNi}$ alloy nanostructures by the reduction of $\mathrm{Ni}(\mathrm{OAc})_{2}$ and $\mathrm{Cu}(\mathrm{OAc})_{2}$ in ethanol using hydrazine hydrate as the reducing agent and poly(ethylene glycol) (PEG) or poly(4-vinyl phenol) (PVPh) as stabilizing-cum-structure-directing agents (Figure 5) [58]. The spherical $\mathrm{CuNi}$ polymer-assisted chain-like nanostructures exhibited a diameter in the range of $8.0 \pm 1.1 \mathrm{~nm}$ (CuNi-PEG) and $7.5 \pm 1.8 \mathrm{~nm}(\mathrm{CuNi}$-PVPh), whilst bare CuNi BMNPs displayed a tendency to be aggregated, proving the role of the polymer as a stabilizer. The saturation magnetization values are $38 \mathrm{emu} \mathrm{g}^{-1}$ for CuNi-PEG and $34 \mathrm{emu} \mathrm{g}^{-1}$ for CuNi-PVPh, being higher than that of bare $\mathrm{CuNi}$ $\left(11.5 \mathrm{emu}^{-1}\right)$, probably due to the presence of oxides on the alloy surface. XPS along with zeta potential analyses confirmed the presence of $\mathrm{Cu}(\mathrm{I})$ on the surface material, promoting its reactivity for alkyne-azide cycloaddition reactions at room temperature both in water and organic solvents, with enhanced recovery (due to the inherent magnetic properties of the BMNPs) and reusability for up to three cycles.

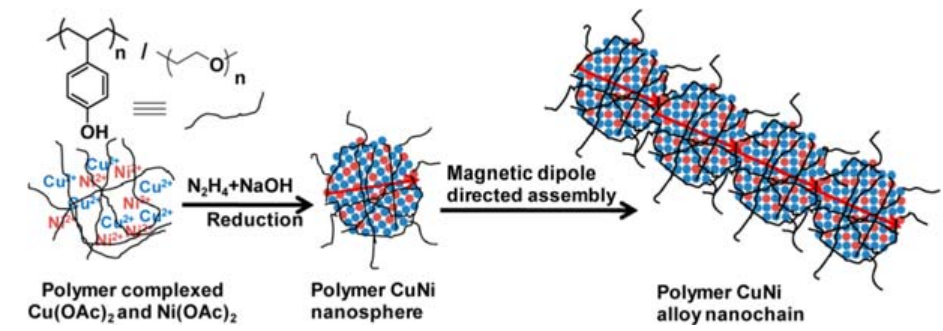

Figure 5. Preparation of CuNi polymer-assisted chain-like alloy nanostructures. Reprinted with permission from reference [58]. Copyright 2014 American Chemical Society. 
Pt-Ru alloy BMNPs were synthesized by the co-reduction of $\mathrm{RuCl}_{3} \cdot 3 \mathrm{H}_{2} \mathrm{O}$ and $\mathrm{H}_{2}\left[\mathrm{PtCl}_{6}\right] \cdot 6 \mathrm{H}_{2} \mathrm{O}$ in the presence of PVP as a protecting polymer in an ethanol/water mixture, where ethanol acts as both the solvent and reducing agent [59]. The formation of $\mathrm{Pt}(0)$ and $\mathrm{Ru}(0) \mathrm{NPs}$ was monitored by UV-Vis. The size, morphology, and composition of BMNPs were determined by TEM-EDX analyses, showing a mean particle size of $3.2 \pm 1.4 \mathrm{~nm}$, which is smaller than the corresponding monometallic nanoparticles (4.6 nm for PtNPs and 4.2 for RuNPs). XPS analysis evidenced the absence of oxidized metallic species, thanks to the protection triggered by PVP on the nanomaterial surface. The PVP-protected Pt-Ru BMNPs were efficient catalysts for the hydrolysis of ammonia borane adduct $\left(\mathrm{H}_{3} \mathrm{~N}-\mathrm{BH}_{3}\right)$ to generate hydrogen with an average TOF of $308 \mathrm{~min}^{-1}$ and a maximum rate of hydrogen generation of 9884 $\mathrm{L}\left(\mathrm{H}_{2}\right) \mathrm{min}^{-1} \mathrm{~mol}_{\mathrm{cat}^{-1}}{ }^{-1}$, along with a calculated activation energy of $56.3 \pm 2 \mathrm{~kJ} \mathrm{~mol}^{-1}$. In comparison with monometallic PtNPs, RuNPs, and an equimolar mixture of them (PtNPs + RuNPs), PtRu BMNPs (1:1) showed higher catalytic activity thanks to the synergistic effect between metal partners, as well as their smaller particle size.

Fe-Pt BMNPs were synthesized by the simultaneous decomposition of $\left[\mathrm{Pt}(\mathrm{acac})_{2}\right](\mathrm{acac}=$ acetylacetonato anion) and $\mathrm{Fe}(\mathrm{CO})_{5}$ at $100{ }^{\circ} \mathrm{C}$ in a mixture of 1,2-hexadecanediol, dioctyl ether and oleic acid (the latter acting as a stabilizer) [60]. The isolated BMNPs capped by oleic acid led to exchange ligand reactions by the addition of other carboxylic acids, including those bearing perfluoro-alkyl substituents; among them, the most stable colloidal solutions were those containing long perfluorinated-alkyl chains. This stabilizer exchange did not trigger any change in the morphology of the Fe-Pt BMNPs, as evidenced by TEM analyses. The BMNPs stabilized by fluorous-based carboxylic acids were notably active in the hydrogenation of cinnamaldehyde and also more selective in relation to the analogous monometallic PtNPs. Actually, Fe-Pt BMNPs capped by long-perfluorous carboxylic acids showed a high chemoselectivity towards the reduction of carbonyl groups, preferentially leading to cinnamyl alcohol (up to 94\%), in contrast to the PtNPs capped by oleic acid, which mainly produced a saturated alcohol, namely hydrocinnamyl alcohol. The authors explain the different behavior of mono- and bimetallic NPs on the basis of the hindrance produced by the adsorption of long-chain ligands around platinum sites, favoring the head-on approach of cinnamaldehyde and then precluding the $\mathrm{C}=\mathrm{C}$ bond hydrogenation.

\subsection{Supported BMNPs in Alcohols}

Pd-Co BMNPs supported on three-dimensional graphene (3DG) were synthesized from $\mathrm{PdCl}_{2}$ and $\mathrm{CoCl}_{2}$ in the presence of ethylene glycol as the reducing, stabilizing, and dispersing agent [61]. The distributed Pd-Co BMNPs on the surface of 3DG exhibited a mean size of 15-25 nm, characterized by TEM. XPS showed the alloy structure for Pd-Co BMNPs, constituted by $\mathrm{Pd}(0), \operatorname{Pd}(\mathrm{II}), \mathrm{Co}(\mathrm{II})$, and $\mathrm{Co}(\mathrm{III})$. The PdCo (1:1) BMNPs-3DG revealed enhanced reactivity towards Sonogashira and Suzuki cross-couplings between terminal alkynes and aryl halides, and phenyl boronic acid and bromobenzene, respectively, when water was used as the solvent. The catalyst was recycled up to seven times, without any change in the morphology of the catalytic material.

Following the same strategy, Ni-Co and Ni-Zn BMNPs supported on graphitized carbon black solid (GCB) were synthesized by the co-reduction of $\mathrm{Ni}\left(\mathrm{NO}_{3}\right)_{2} \cdot 6 \mathrm{H}_{2} \mathrm{O}$ and $\mathrm{Co}\left(\mathrm{NO}_{3}\right)_{2} \cdot 6 \mathrm{H}_{2} \mathrm{O}$ or $\mathrm{Zn}\left(\mathrm{NO}_{3}\right)_{2} \cdot 6 \mathrm{H}_{2} \mathrm{O}$, according to the surfactant-aided polyol reduction method, using ethylene glycol as the solvent, reducing agent, and protecting agent, and $\mathrm{H}_{2}\left[\mathrm{PtCl}_{6}\right]$ as the heterogeneous nucleation seeds [62]. The formation of Ni-Co and Ni-Zn alloy nanostructures was elucidated by XRD, XPS, and TEM techniques. The powder XRD evidenced the lattice of face-centered cubic (fcc) structured Ni and

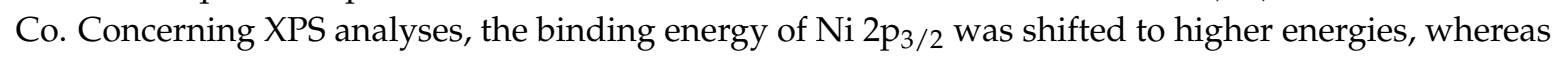
the binding energy of $\mathrm{Zn} 2 \mathrm{p}_{3 / 2}$ appeared shifted to lower energies, compared to the corresponding monometallic counterparts; these data confirm the modification of the electronic properties of $\mathrm{Ni}$ and $\mathrm{Zn}$ in the NiZn alloy nanostructures. These catalysts were efficient for the gasification of phenol under supercritical water at $450{ }^{\circ} \mathrm{C}\left(\mathrm{Ni}_{20} \mathrm{Co}_{15}\right.$ favors $\mathrm{H}_{2}$ production with a calculated activation energy of $43.6 \pm 2.6 \mathrm{~kJ} / \mathrm{mol}$ and $\mathrm{Ni}_{20} \mathrm{Zn}_{15}$ favors $\mathrm{CH}_{4}$ production with a calculated activation energy of 
$20.4 \pm 2.6 \mathrm{~kJ} / \mathrm{mol}$ ). However, BMNPs showed a tendency to be agglomerated and consequently, the specific surface area decreased, resulting in a drop in catalytic reactivity [62]. Lua and Shen reported the polyol synthesis of Ni-Cu BMNPs alloys supported on carbon nanotubes (CNTs) from $\mathrm{Ni}\left(\mathrm{NO}_{3}\right)_{2} \cdot 6 \mathrm{H}_{2} \mathrm{O}$ and $\mathrm{Cu}\left(\mathrm{NO}_{3}\right)_{2} \cdot 3 \mathrm{H}_{2} \mathrm{O}$ in the presence of PVP and ethylene glycol. The as-prepared Ni-Cu@CNTs were employed as catalysts for the $\mathrm{H}_{2}$ production by $\mathrm{CH}_{4}$ decomposition $[63,64]$.

Table 2. Bimetallic nanoparticles in alcohols applied in catalysis. ${ }^{\text {a) }}$

\begin{tabular}{|c|c|c|c|c|c|c|}
\hline Entry & $\begin{array}{c}\text { BMNPs } \\
\text { (Mean Size, nm) }\end{array}$ & Structure & Metallic Precursors & $\begin{array}{l}\text { Synthetic } \\
\text { Procedure }\end{array}$ & $\begin{array}{l}\text { Catalytic } \\
\text { Reaction }\end{array}$ & Refs. \\
\hline 1 & $\mathrm{CuNi}(8)$ & alloys & $\begin{array}{l}\mathrm{Ni}(\mathrm{OAc})_{2} \\
\mathrm{Cu}(\mathrm{OAc})_{2}\end{array}$ & co-reduction & $\begin{array}{l}\text { alkyne-azide } \\
\text { cycloaddition }\end{array}$ & [58] \\
\hline 2 & PtRu (3.2) & alloys & $\begin{array}{c}\mathrm{RuCl}_{3} \cdot 3 \mathrm{H}_{2} \mathrm{O} \\
\mathrm{H}_{2}\left[\mathrm{PtCl}_{6}\right] \cdot 6 \mathrm{H}_{2} \mathrm{O}\end{array}$ & co-reduction & $\begin{array}{l}\mathrm{H}_{3} \mathrm{~N}-\mathrm{BH}_{3} \\
\text { hydrolysis }\end{array}$ & [59] \\
\hline 3 & $\mathrm{FePt}(3.2-3.6)$ & alloys & {$\left[\mathrm{Pt}(\mathrm{acac})_{2}\right], \mathrm{Fe}(\mathrm{CO})_{5}$} & co-reduction & hydrogenations & [60] \\
\hline 4 & PdCo@3DG (15-25) & alloys & $\mathrm{PdCl}_{2}, \mathrm{CoCl}_{2}$ & co-reduction & $\begin{array}{l}\text { Sonogashira and } \\
\text { Suzuki couplings }\end{array}$ & [61] \\
\hline 5 & NiCu@CNTs (25-42) & alloys & $\begin{array}{l}\mathrm{Ni}\left(\mathrm{NO}_{3}\right)_{2} \cdot 6 \mathrm{H}_{2} \mathrm{O}, \\
\mathrm{Cu}\left(\mathrm{NO}_{3}\right)_{2} \cdot 3 \mathrm{H}_{2} \mathrm{O}\end{array}$ & co-reduction & $\begin{array}{c}\mathrm{CH}_{4} \\
\text { decomposition }\end{array}$ & {$[63,64]$} \\
\hline
\end{tabular}

a) For abbreviations: n.r. = not reported; $3 \mathrm{DG}=$ three-dimensional graphene; $\mathrm{CNTs}=$ carbon nanotubes.

\section{Ionic Liquids and Deep Eutectic Solvents}

\subsection{Ionic Liquids}

Ionic liquids (ILs) exhibit distinctive physico-chemical properties (low vapor pressure, wide temperature range for the liquid phase, low coordinative properties, thermal and chemical stability, broad electrochemical window); these features permit one to control the assembling, size, and shape of metal nano-systems $[65,66]$. Although the contributions concerning mono-metallic and metal oxide nanoparticles have received a greater interest by the scientific community [67-69], BMNPs in ionic liquids are quickly appearing in the literature, mainly concerning late transition metals [see the following selected contributions [70-74]. Prechtl and Gómez groups have recently reviewed the synthesis of BMNPs in ILs for catalytic purposes [67,75]. Hereafter, we describe the works of BMNPs in ionic liquids applied in catalysis, organized according to the two main synthetic methodologies involved in their syntheses: (i) co-decomposition of two metal precursors; and (ii) sequential processes, where the first decomposed metal precursor acts as a seed for the deposition of the second one; chemical and physical strategies have been carried out for both approaches. For a summary of the BMNPs in ionic liquids, including Deep Eutectic Solvents, applied in catalysis, see Table 3 at the end of Section 4.

\subsubsection{Synthesis of BMNPs in Ionic Liquids by Co-Decomposition of Metal Precursors}

AuPd BMNPs represent the most studied bimetallic systems applied in catalysis. Yan and co-workers prepared AuPd BMNPs by the co-decomposition of $\mathrm{Au}(\mathrm{OAc})_{3}$ and $\mathrm{Pd}(\mathrm{OAc})_{2}$ in $\left[\mathrm{C}_{2} \mathrm{OHmim}\right]\left[\mathrm{NTf}_{2}\right]$ at $100{ }^{\circ} \mathrm{C}$ for $2 \mathrm{~h}$ under vacuum [76]. The size of the resulting BMNPs was independent of the $\mathrm{Au} / \mathrm{Pd}$ ratio involved: in all cases, the mean diameter was ca. $4-5 \mathrm{~nm}$. The mass percentage of $\mathrm{Au}$ and Pd in each type of BMNP was determined by STEM-EDX and was in agreement with the initial ratio of the molecular precursors. XRD analyses only showed Au diffraction peaks, and no crystalline domains of Pd were detected. The composition of the outer layer of BMNPs was determined by XPS. For the $\mathrm{Au}_{0.8} \mathrm{Pd}_{0.2}, \mathrm{Au}_{0.5} \mathrm{Pd}_{0.5}$, and $\mathrm{Au}_{0.2} \mathrm{Pd}_{0.8}$ ratios, as described for the synthesis, an enrichment in Pd was observed for the two first BMNPs (Au/Pd ratios are 56/44, 34/66 and 25/75, respectively, estimated from the intensity of XPS peaks). These XPS peaks correspond to $\mathrm{Au}(0)$ and $\mathrm{Pd}(0)$ in the case of the $\mathrm{Au}_{0.8} \mathrm{Pd}_{0.2}$ and $\mathrm{Au}_{0.5} \mathrm{Pd}_{0.5}$ samples, and a $30 \%$ level of $\mathrm{Pd}(\mathrm{II})$ could also be detected. Overall, the higher content of Au triggered an increase in \%Pd (II) in the BMNPs. XPS data evidence a partial core-shell structure for these BMNPs. These BMNPs were applied in the 
one-pot multi-step hydrogenation/hydrodechlorination process of 2-chloronitrobenzene to selectively furnish cyclohexylamine, observing that the catalytic activity rises with the Au content, evidencing the synergic effect between both metals (Scheme 2). It could be noted that under the same conditions, monometallic AuNPs were inactive, and PdNPs showed a high selectivity towards the reduction of the nitro group alone (2-chloroaniline/aniline/cyclohexylamine $=85 / 7 / 8$ ). These BMNPs were also efficient for the hydrodehalogenation of 4-bromotoluene and the 3,5-dibromotoluene to afford toluene.

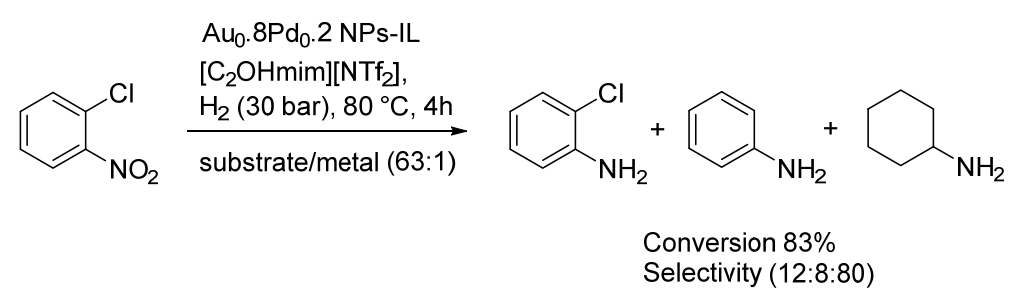

Scheme 2. AuPd BMNPs applied in the one-pot multi-step hydrodechlorination/hydrogenation process of 2-chlorotoluene [76].

Scott and co-workers have prepared Au-Pd BMNPs by the co-decomposition of $\mathrm{H}\left[\mathrm{AuCl}_{4}\right]$ and $\mathrm{K}_{2}\left[\mathrm{PdCl}_{4}\right]$ in $\left[\mathrm{C}_{1} \mathrm{C}_{4} \mathrm{Im}\right]\left[\mathrm{PF}_{6}\right]\left(\left[\mathrm{C}_{1} \mathrm{C}_{4} \mathrm{Im}\right]=1\right.$-butyl-3-methylimidazolium), using $\mathrm{NaBH}_{4}$ as a reducing agent in the absence of any added stabilizer, yielding polydispersed NPs [77]. Alternatively, they tested the preparation of AuPd NPs in methanol in the presence of poly(vinylpyrrolidone) (PVP), which acted as the stabilizer. After the reduction, the colloidal methanol solution was transferred into $\left[\mathrm{C}_{1} \mathrm{C}_{4} \mathrm{Im}\right]\left[\mathrm{PF}_{6}\right]$ and the methanol was then removed under low pressure. No details are given in relation to the structure of the as-prepared nanocatalysts. However, the absence of the corresponding Au plasmon band in the UV-Vis spectra for these BMNPs dispersed in IL, seems to point to the formation of a bimetallic system. Au-Pd BMNPs constituted by different $\mathrm{Au} / \mathrm{Pd}$ ratios $(3 / 1,1 / 1$, and $1 / 3)$ were applied in the hydrogenation of allyl alcohol, cycloocta-1,3-diene, (E)-cinnamaldehyde, and 3-hexyn-1-ol; nanocatalysts with an Au:Pd ratio (1:3) showed the highest catalytic activity (Scheme 3) [78]. Moreover, the authors showed that PVP was the best stabilizer (among 1-methylimidazole and 1-(2'-aminoethyl)-3-methylimidazolium hexafluorophosphate) for the preparation of Au-Pd BMNPs for 3-buten-1-ol hydrogenation [79].

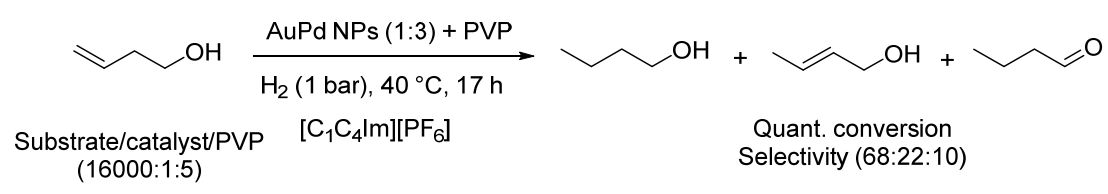

Scheme 3. AuPd BMNPs applied in the hydrogenation of 3-buten-1-ol [79].

AuPd and AuPt alloys have been prepared by the simultaneous sputtering of the corresponding metals by Torimoto and co-workers [80,81]. The simultaneous sputtering of $\mathrm{Au}$ and $\mathrm{Pt}$ starting from six targets with different metal mixtures using $N, N, N$-trimethyl- $N$-propylammonium bis(trifluoromethanesulfonyl)amide (TMPA-TFSA), led to the formation of small AuPt BMNPs (mean diameter less than $2 \mathrm{~nm}$ ). XRD analyses suggest the formation of an AuPt alloy phase, also confirmed by the peak current intensity, which was 20 times higher than the corresponding monometallic AuNPs electrodes in the methanol electrocatalytic oxidation [80] (for AuPt NPs with $\mathrm{Au} / \mathrm{Pt}$ ratio 1/3). The same group described the synthesis of AuPd alloys in $\left[\mathrm{BMI}_{[}\left[\mathrm{PF}_{6}\right]\right.$ following the same methodology. In this case, $\mathrm{Au}_{0.5} \mathrm{Pd}_{0.5} \mathrm{NPs}$ (mean diameter ca. $2 \mathrm{~nm}$ ) were the most active for the electroxidation of ethanol [81].

$\mathrm{Au}$-Pd alloys supported on solids have also been reported. Therefore, Wang and co-workers applied the sputtering co-reduction method for the synthesis of Au-Pd BMNPs in $\left[C_{1} C_{4} \operatorname{Im}\right]\left[\mathrm{BF}_{4}\right]$ immobilized on multi-walled carbon nanotubes (MWCNTs) [82]. The as-obtained BMNPs showed an alloy structure, as deduced from HAADF-STEM analysis. These materials were applied to the 
conversion of 4-nitrophenol into 4-aminophenol by $\mathrm{NaBH}_{4}$ in water, followed by UV-vis analyses. A higher activity was found for the as-prepared BMNPs than that observed using supported monometallic PdNPs on MWCNTs. Guo's group prepared Pd-Ni BMNPs anchored on MWCNTs by thermal decomposition for electrocatalytic applications, mainly the electro-oxidation of alcohols [83,84].

Platinum-based BMNPs containing a p block metal were prepared by Dietrich et al. Pt-Sn alloys were synthesized by the co-reduction of $\mathrm{PdCl}_{2}$ and $\mathrm{SnCl}_{2}$ or $\mathrm{Sn}(\mathrm{OAc})_{2}$ in methyltrioctyl ammonium bis(trifluoromethylsulfonyl)imide ([OMA][NTf $\left.{ }_{2}\right]$ ) and using methyltrioctyl ammonium borohydride as the reductant [85]. Each catalyst featuring different Pt-Sn ratios showed almost the same mean size, in the range of $2-3 \mathrm{~nm}$. These BMNPs were used after precipitation or extraction from the IL phase for the hydrogenation of cinnamaldehyde in THF. When monometallic PtNPs were used, cinnamaldehyde gave exclusively hydrocinnamic aldehyde. However, Pt-Sn BMNPs constituted by a $1 / 1$ or $3 / 1 \mathrm{Pt} / \mathrm{Sn}$ ratio only gave cinnamic alcohol. Furthermore, the latter system led to the higher TOF $\left(28 \mathrm{~h}^{-1}\right)$ (Scheme 4) [85].

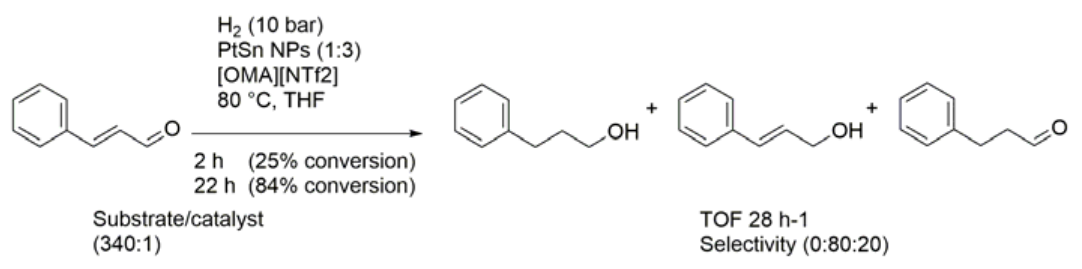

Scheme 4. PdSn-based BMNPs stabilized by $[\mathrm{OMA}]\left[\mathrm{NTf}_{2}\right]$ as the catalyst for the hydrogenation of cinnamaldehyde [85].

BMNPs containing ruthenium and a first-row transition metal, e.g., copper and iron, have been efficiently prepared in ILs. Santini and co-workers synthesized Ru-Cu core-shell BMNPs in $\left[\mathrm{C}_{1} \mathrm{C}_{4} \mathrm{Im}\right]\left[\mathrm{NTf}_{2}\right]$ from $\left(\eta^{4}-1,5\right.$-cyclooctadiene) $\left(\eta^{6}-1,3,5\right.$-cyclooctatriene)ruthenium( 0$)$, [Ru(cod)(cot)], and mesitylcopper(I), [CuMes], by simultaneous decomposition at $100{ }^{\circ} \mathrm{C}$ under 9 bar $\mathrm{H}_{2}$ for $4 \mathrm{~h}$ [86]. The mean diameter $\left(\mathrm{d}_{\text {mean }}\right)$ of the resulting BMNPs was smaller than that corresponding to monometallic NPs: for RuNPs, $d_{\text {mean }}=4 \mathrm{~nm}$; for CuNPs, $d_{\text {mean }}=5.1 \mathrm{~nm}$; for Ru@CuNPs, the mean diameter was in the range from 1.8 to $3.4 \mathrm{~nm}$ by increasing the amount of copper from 0.005 to 0.9 . These BMNPs were applied in the hydrogenation of benzene in order to obtain information about the cooperative effect of both metals (Scheme 5). Actually, by increasing the amount of copper, the full hydrogenation of benzene into cyclohexane decreased, showing that copper can also be present on the surface of nanoparticles in close proximity to ruthenium [86].

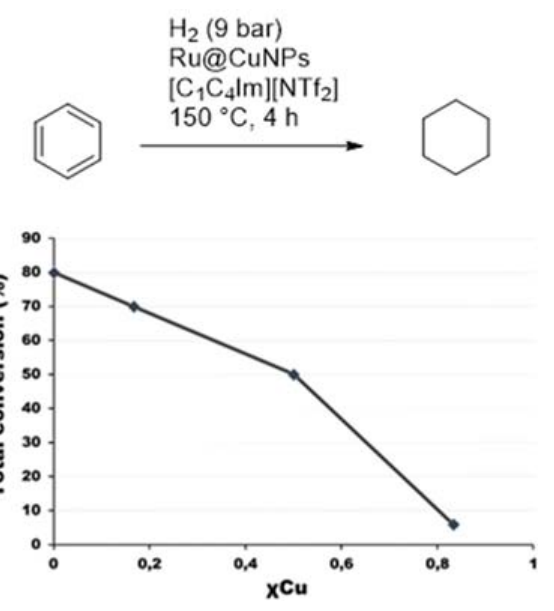

Scheme 5. Conversion as a function of the molar fraction of $\mathrm{Cu}$ in bimetallic $\mathrm{Ru}-\mathrm{Cu}$ NPs for the hydrogenation of benzene. Reproduced from reference [86] with the permission of Springer. 
Baiker and co-workers synthesized Fe-Ru BMNPs in $\left[\mathrm{C}_{1} \mathrm{C}_{4} \operatorname{Im}\right]\left[\mathrm{PF}_{6}\right]$ and $\left[\mathrm{C}_{1} \mathrm{C}_{4} \operatorname{Im}\right]\left[\mathrm{BF}_{4}\right]$ from diironnonacarbonyl $\left[\mathrm{Fe}_{2}(\mathrm{CO})_{9}\right]$ and triruthenium-dodecacarbonyl $\left[\mathrm{Ru}_{3}(\mathrm{CO})_{12}\right]$ by simultaneous decomposition at $250{ }^{\circ} \mathrm{C}$ for $18 \mathrm{~h}$ [87]. Fe-Ru BMNPs with different Fe/Ru ratios (1/0, 9/1, 3/1, $1 / 1,0 / 1$ ) were applied in the hydrogenation of cyclohexen-2-one (Scheme 6). In $\left[\mathrm{C}_{1} \mathrm{C}_{4} \operatorname{Im}\right]\left[\mathrm{BF}_{4}\right]$, the monometallic RuNPs were more active than FeNPs $(94 \%$ and $33 \%$ conversion, respectively, after $1 \mathrm{~h}$ at $50{ }^{\circ} \mathrm{C}$ under 50 bar $\mathrm{H}_{2}$ ). The reactivity of the Fe-Ru BMNPs increases with the amount of $\mathrm{Ru}$ (from 22 to $91 \%$ conversion for the different Fe/Ru ratios). The catalytic behavior of the FeRuNPs $1 / 1$ is quite similar to that observed using monometallic RuNPs. Recycling experiments evidenced a deactivation of the iron containing catalysts; however, only Fe-Ru BMNPs $1 / 1$ in $\left[\mathrm{C}_{1} \mathrm{C}_{4} \mathrm{Im}\right]\left[\mathrm{BF}_{4}\right]$ maintained their activity after recycling. The presence of $\mathrm{CO}_{2}\left(60\right.$ bar for 30 bar pressure of $\left.\mathrm{H}_{2}\right)$ increases the hydrogenation rate (full conversion after $30 \mathrm{~min}$ ); no consecutive hydrogenation of cyclohexanone was observed. It is well-known that the presence of $\mathrm{CO}_{2}$ enhances the mass transfer in the reaction medium by diminishing the viscosity of the IL and increasing the solubility of $\mathrm{H}_{2}[88,89]$.

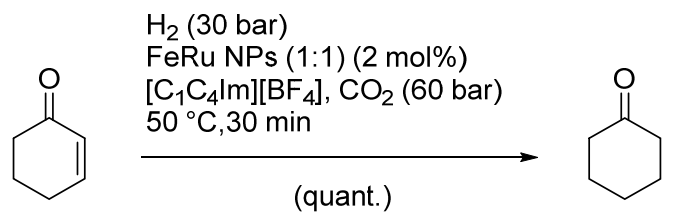

Scheme 6. FeRu BMNPs applied in the hydrogenation of cyclohexen-2-one [87].

BMNPs containing two first row transition metals, $\mathrm{Cu}-\mathrm{Zn}$ alloy nano-systems, have been prepared by Janiak and co-workers [90]. $\mathrm{Cu} / \mathrm{Zn}$ brass alloy NPs were synthesized by the decomposition of the corresponding amidinate precursors under microwave irradiation in $[\mathrm{BMIm}]\left[\mathrm{PF}_{6}\right]\left(\mathrm{Scheme}_{\mathrm{a}} \mathrm{a}\right)$.

a)

a) ip
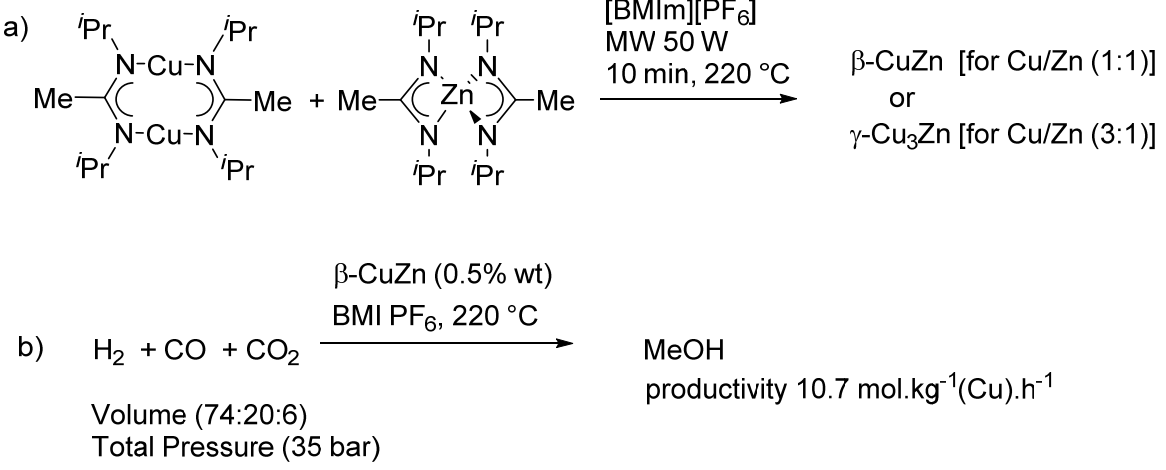

$\mathrm{MeOH}$

productivity $10.7 \mathrm{~mol} \cdot \mathrm{kg}^{-1}(\mathrm{Cu}) \cdot \mathrm{h}^{-1}$

Scheme 7. (a) Synthesis of CuZn alloys in $\left[\mathrm{C}_{1} \mathrm{C}_{4} \mathrm{Im}\right]\left[\mathrm{PF}_{6}\right]$ by the decomposition of amidinate precursors under microwave activation. (b) Production of methanol catalyzed by the $\beta$-CuZn alloy [90].

As confirmed by XPS, the phase composition of the alloy nanoparticles is coherent with the $\mathrm{Cu} / \mathrm{Zn}$ ratio of the precursors used in their syntheses. The homogeneous distribution of this phase was checked by local resolution EDX throughout single nanoparticles for a mean diameter of 45-50 nm and powder XRD data correspond to $\beta-\mathrm{CuZn}$ for $\mathrm{Cu} / \mathrm{Zn}=1 / 1$ and to $\gamma-\mathrm{CuZn}$ for $\mathrm{Cu} / \mathrm{Zn}=3 / 1$. This $\beta$-CuZn colloidal solution was used as a catalyst for the synthesis of methanol (Scheme $7 \mathrm{~b}$ ). After catalysis, $\mathrm{ZnO}$ was detected undergoing morphological changes but no size changes [90]. $\mathrm{ZnO}$ is probably produced during the induction period observed in the formation of methanol.

$\mathrm{NiGa} N \mathrm{Ns}$ were prepared under microwave irradiation by the simultaneous pyrolysis of [Ni(cod $\left.)_{2}\right]$ and $\mathrm{GaCp} *$ with a $1 / 1$ and 3/1 molar ratio in $\left[\mathrm{C}_{1} \mathrm{C}_{4} \mathrm{Im}\right]\left[\mathrm{BF}_{4}\right]$ at $50 \mathrm{~W}$ and $220{ }^{\circ} \mathrm{C}$ for $10 \mathrm{~min}$ [91]. The mean diameter of both BMNPs was 7-29 $\mathrm{nm}$ and 12-19 $\mathrm{nm}$ for the Ni/Ga (1:1) and (3:1) molar ratios, respectively. The formation of single crystalline $\mathrm{Ni}-\mathrm{Ga}$ was evidenced by powder $\mathrm{XRD}$ in comparison 
with Ni-Ga reference peaks, and the homogeneous phase of $\mathrm{Ni}_{3} \mathrm{Ga}$ was determined by EDX. Ni-Ga BMNPs were applied as catalysts in the hydrogenation of terminal and internal alkynes (Scheme 8). In comparison to NiNPs, the activity of bimetallic catalysts was lower. However, Ni-Ga BMNPs were selective towards the formation of the corresponding alkenes under smooth conditions $\left(1 \mathrm{bar} \mathrm{H}_{2}\right.$, $40^{\circ} \mathrm{C}$ ), in contrast to monometallic NiNPs which gave the corresponding saturated compounds [91]. The catalytic phase was recycled up to four times with an insignificant loss of activity or selectivity.

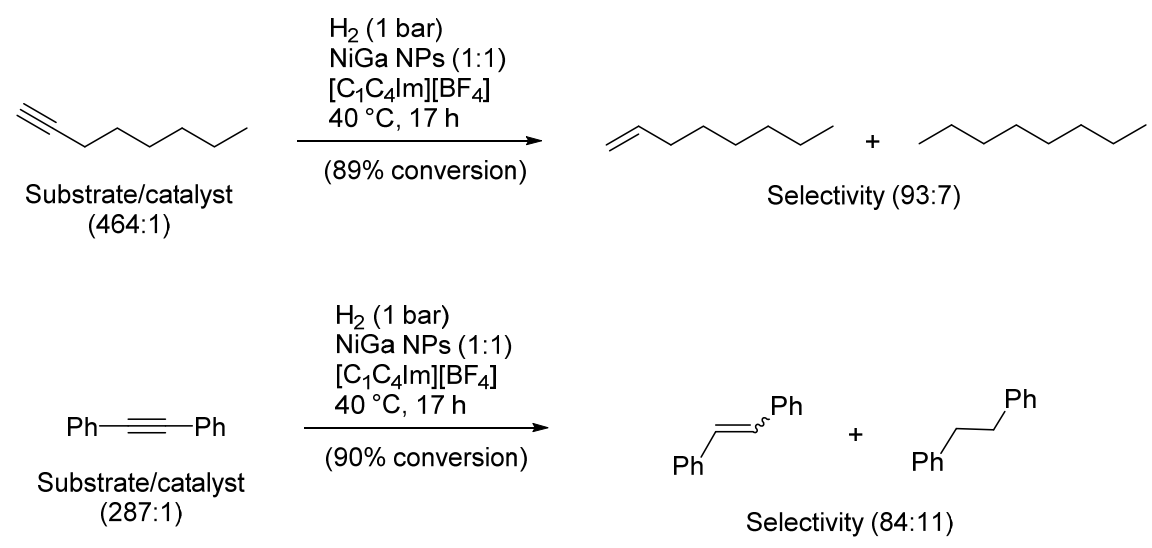

Scheme 8. Semihydrogenation of alkynes catalyzed by NiGa BMNPs [91].

\subsubsection{Synthesis of BMNPs in Ionic Liquids by Sequential Process}

$\mathrm{Au}-\mathrm{Pd}$ BMNPs were synthesized by a sequential procedure, first reducing $\mathrm{H}\left[\mathrm{AuCl}_{4}\right] \cdot 4 \mathrm{H}_{2} \mathrm{O}$ by $\mathrm{LiBH}_{4}$, followed by the reduction of $\mathrm{K}_{2}\left[\mathrm{PdCl}_{4}\right]$ by ascorbic acid, both in water and in tris(hexyl)(tetradecyl)phosphonium chloride [42]. No information about the structure of these BMNPs was given. These Au-Pd BMNPs were applied to the oxidation of $\alpha, \beta$-unsaturated alcohols in the presence of molecular oxygen (Scheme 9). The activity of these nanocatalysts was higher in IL than in water, but Au-Pd BMNPs did not present a significant difference with the corresponding monometallic PdNPs in terms of activity or selectivity. After catalysis, an increase in the size of NPs was observed, ranging from 3.7 to $10 \mathrm{~nm}$ for Au-Pd BMNPs (1:3) and from 4.3 to $9.0 \mathrm{~nm}$ for PdNPs.

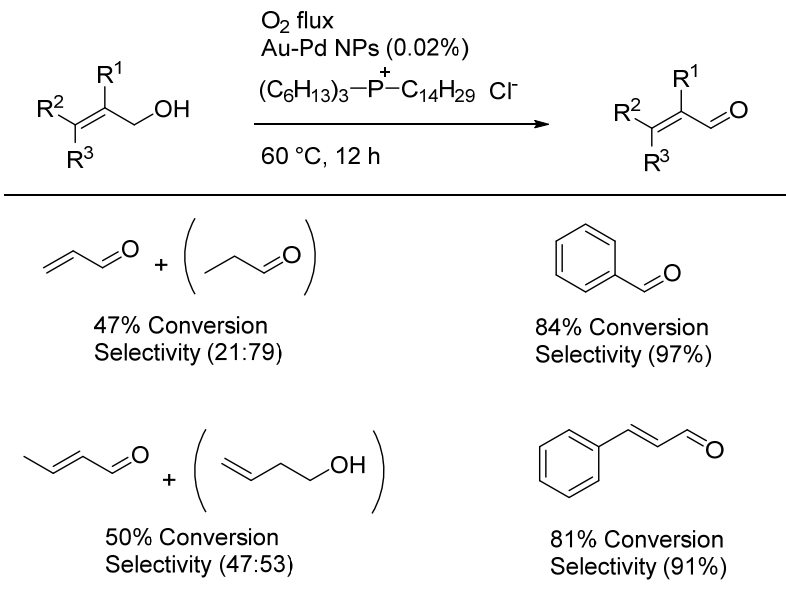

Scheme 9. AuPd BMNPs catalyzed the selective oxidation of $\alpha, \beta$-unsaturated alcohols to aldehydes [42].

$\mathrm{Ru} @ \mathrm{Pt}$ core-shell nanoparticles were prepared by the reduction of [Ru(2-methylallyl $\left.)_{2}(\mathrm{cod})\right]$ (cod $=1,3$-cyclooctadiene) in $\left[\mathrm{C}_{1} \mathrm{C}_{4} \mathrm{Im}\right]\left[\mathrm{PF}_{6}\right]$ at $75^{\circ} \mathrm{C}$ for $18 \mathrm{~h}$ under 5 bar of hydrogen, followed by the addition of $\left[\mathrm{Pt}_{2}(\mathrm{dba})_{3}\right]$ ( $\mathrm{dba}=$ dibenzylideneacetone) under 4 bar of $\mathrm{H}_{2}$ at $75{ }^{\circ} \mathrm{C}$ for $18 \mathrm{~h} \mathrm{[92]}$. 
These BMNPs showed a mean size of $2.9 \mathrm{~nm}$. Rutherford Back Scattering (RBS) analysis indicated a composition of (2:1) Pt/Ru, which represents half the amount of the Ru precursor initially used. The HAADF-STEM and the single particle EDS analyses indicated a Pt rich BMNPs. XPS analyses evidenced three oxidation states for Pt (0, II, and IV) with $9 \%, 25 \%$, and $66 \%$, respectively, and only $\mathrm{Ru}(0)$, which represents $11 \%$. Moreover, the Ru rich core composition was determined by a comparison of the ratio between Pt4f/Ru3d intensities for both binding energies (3000 and $1840 \mathrm{eV} \mathrm{for} \mathrm{Pt4f} \mathrm{and}$ Ru3d, respectively) and through evidence that this ratio decreases with the increase of the binding energies (which is related to the depth of the probe and so to the Ru concentration). These NPs were used as catalysts for the hydrogenation of benzene. It appeared that after catalysis the surface composition had changed (with an enrichment of $\mathrm{Pt}$ and a change in the composition (for $\mathrm{Pt}(0), \mathrm{Pt}(\mathrm{II})$, and $\mathrm{Pt}(\mathrm{IV}), 43 \%, 46 \%$, and $11 \%$, respectively; for $\mathrm{Ru}(0), 31 \%)$, inducing a different selectivity. Ru@Pt NPs showed a higher selectivity towards the formation of cyclohexene, in comparison to the selectivity obtained with the corresponding monometallic RuNPs and PtNPs at $1 \%$ substrate conversion. This behavior clearly evidenced the influence of Ru on the activity of Pt in the BMNPs system.

Supported Au-Pd BMNPs prepared in RTILs (Room Temperature Ionic Liquids) following a sequential methodology have been described by Wang's group [93-95]. The role of the RTIL is multiple: it permits a uniform decoration of the BMNPs on the support thanks to a homogeneous dispersion of the support and BMNPs in the IL; it acts as a linker to better immobilize the metal nanoparticles on the support; and it favors the sputtering onto a liquid under high-vacuum conditions, due to its low vapor pressure. By this technique, Au-Pd BMNPs on $\mathrm{TiO}_{2}$ were prepared by the successive sputtering of first $\mathrm{Au}$ and then $\mathrm{Pd}$ onto a suspension of $\mathrm{TiO}_{2}$ in $\left[\mathrm{C}_{1} \mathrm{C}_{4} \mathrm{Im}\right]\left[\mathrm{BF}_{4}\right]$. These materials were isolated from the IL suspension by centrifugation and decantation. The characterization of these bimetallic systems with different Pd/Au ratios [TEM, EDX, HAADF-STEM (High-Angle-Annular-Dark-Field Scanning Transmission Electron Microscopy), UV-Vis spectra] revealed alloy structures. The best activity for the oxidation of phenylethanol into acetophenone was found using Pd/Au catalysts of a (1:1) ratio under solvent-free conditions and $\mathrm{O}_{2}$ atmosphere $(1 \mathrm{~atm})$ as the oxidant. The authors explained the increase in activity of the BMNPs in relation to the corresponding monometallic ones by both the fact that BMNPs are smaller than AuNPs ( $3 \mathrm{~nm}$ vs. $5 \mathrm{~nm}$ ) and the synergetic effect between Pd and Au, which limits the reactant adsorption on Au [93]. Alloy-based AuPd BMNPs were prepared in the same way and supported on graphene [94]. These catalytic materials were applied in the oxidation of cis-cyclooctene by TBHP (tert-butyl hydroperoxide) under solvent-free conditions; the catalyst exhibiting a (1:2) ratio $\mathrm{Pd} / \mathrm{Au}$ was the most active system. These catalysts were also tested in the reduction of 4-nitrophenol by $\mathrm{NaBH}_{4}$ in aqueous solution and in this case, the best $\mathrm{Pd} / \mathrm{Au}$ catalytic system was that showing a (1:1) Pd/Au composition. This differential behavior evidences the crucial effect of the charge distribution and also the surface composition for catalytic applications [95]. Ag-Au and Ag-Pd BMNPs supported on graphene were also prepared using a similar method, presenting core-shell structures, where the core is Ag-based and a partial alloying Ag-Au or Ag-Pd takes place at the shell. These BMNPs showed higher activity for the reduction of 4-nitrophenol by $\mathrm{NaBH}_{4}$ in water (monitored by UV-vis analyses), than the corresponding monometallic Au and Pd NPs on graphene [93].

\subsection{Deep Eutectic Solvents}

Deep Eutetic Solvents (DESs) are often considered as alternative media in relation to room temperature ionic liquids (neat salts); however, they exhibit different compositions and physico-chemical properties. In general, a DES is constituted by a mixture of at least two components, a hydrogen bond donor (commonly carboxylic acids, urea, or polyols) and a hydrogen bond acceptor (such as choline, phosphonium, or sulfonium salts) [95], including Natural DESs, which represent alternative media to water [96]. In the last decade, DESs have been successfully applied in catalysis, including organocatalysis, bio-transformations, and metal-catalyzed organic processes [97-99]. Moreover, these new solvents have found applications in the synthesis of nanomaterials [100-102]. 
In the last years, metal nanoparticles have been synthesized in DESs, such as AgNPs $[103,104]$ and AuNPs [105], as well as $\mathrm{Cu}_{2} \mathrm{ZnSnS}_{4}$ hybrid materials for photovoltaic purposes [106]. Next, we describe BMNPs prepared in DES medium for catalytic applications.

An electrochemical technique has recently been described for producing a core-shell structure for Au@Pd NPs in a deep eutectic solvent [107]. This procedure consists of an anodic dissolution of gold and palladium wires and their simultaneous electrodeposition on a graphite cathode at a constant current density ( $20 \mathrm{~mA} \cdot \mathrm{cm}^{-2}$ for $\mathrm{Pd}$ and $40 \mathrm{~mA} \cdot \mathrm{cm}^{-2}$ for $\left.\mathrm{Au}\right)$ in a mixture of choline chloride and ethylene glycol (choline chloride:ethlylene glycol = 1:2 molar ratio). The consumption of palladium was five times higher than that corresponding to gold, due to the higher solubility of Pd than $\mathrm{Au}$ in this medium; however, the electrochemical reduction of $\mathrm{Au}$ was faster than that of $\mathrm{Pd}$, where $\mathrm{Au}$ nuclei were first formed acting as seeds for Pd deposition. The resulting core-shell structure was proven by cyclic voltammetry using the NPs modified electrode in acidic medium constituted by metal oxides. The peaks observed after stripping corresponded to both PdO and AuO of the BMNPs, which were slightly shifted in comparison with the corresponding monometallic oxides. The consecutive electrochemical cycles led to an intensity diminution of the PdO peak reduction and the concomitant increasing of the peak of AuO (Figure 6). EDX analyses of both these AuPd NPs (after electrodeposition and after electrochemical treatment) also evidenced the core-shell structure. These BMNPs were tested as catalysts for methanol oxidation in alkaline medium [107].
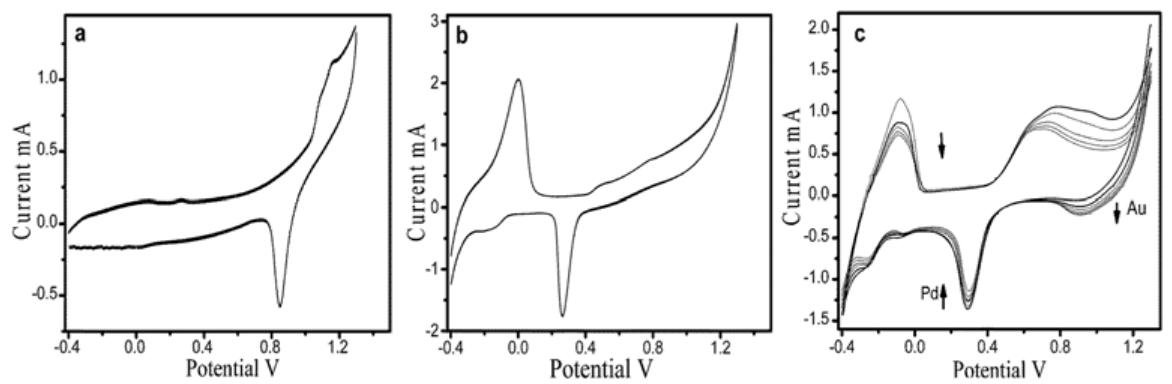

Figure 6. Cyclic voltammograms of graphite rod modified with nanoparticles of (a) $\mathrm{Au}(\mathbf{b}) \mathrm{Pd}$ (c) $\mathrm{Au} @ \mathrm{Pd}$ in $0.5 \mathrm{M} \mathrm{H}_{2} \mathrm{SO}_{4}$ at a scan rate of $100 \mathrm{mV} \mathrm{s}^{-1}$ vs. SCE (Saturated Calomel Electrode). Reproduced from reference [107] with permission of The Royal Society of Chemistry.

Alloys constituted by bimetallic Pd-Sn NPs supported on MWCNT were prepared in a choline chloride:urea mixture (1:2 molar ratio) by the reduction of $\mathrm{PdCl}_{2}$ and $\mathrm{SnCl}_{2}$ with $\mathrm{NaBH}_{4}$ at $150{ }^{\circ} \mathrm{C}$ for $12 \mathrm{~h}$. After the synthesis, the corresponding BMNPs were isolated by centrifugation. XRD, HRTEM, EDX, and HAADF-STEM analyses confirmed the formation of an alloy structure and XPS spectra evidenced the presence of palladium oxide in the as-prepared material ( $23 \%$ of $\mathrm{PdO})$ and also a small proportion of Sn(II) and Sn(IV) oxides. These PdSn BMNPs were applied in the electrooxidation of formic acid [108].

$\mathrm{Ni}-\mathrm{NiN}_{3}$ nanocomposites were prepared by pyrolysis of the $\mathrm{Ni}(\mathrm{OAc})_{2} / \mathrm{DES}$ mixture. This mixture was constituted by $\mathrm{Ni}(\mathrm{OAc})_{2} \cdot 4 \mathrm{H}_{2} \mathrm{O}$ :choline chloride:urea (0.5:1:2 molar ratio), forming a gel which was pyrolyzed at $320^{\circ} \mathrm{C}, 425^{\circ} \mathrm{C}$, and $600{ }^{\circ} \mathrm{C}$. XRD analyses of the three composites gave identical diffractograms for the crystalline structure of metallic nickel(0). The composition of these hybrid materials at the surface was determined by XPS. Amorphous phases of $\mathrm{Ni}(\mathrm{OH})_{2}$ and $\mathrm{NiN}_{3}$ were evidenced; the corresponding binding energy peaks in the region of $\mathrm{Ni} 2 \mathrm{p}_{3 / 2}$ were slightly shifted in comparison to those of the nickel( 0 ) and the corresponding peaks for the pyrolyzed sample at $425^{\circ} \mathrm{C}$ were more intense, pointing to a higher concentration of $\mathrm{Ni}(\mathrm{OH})_{2}$ and $\mathrm{NiN}_{3}$ at the surface [109]. 
Table 3. Bimetallic nanoparticles in ionic liquids applied in catalysis. ${ }^{a}$

\begin{tabular}{|c|c|c|c|c|c|c|}
\hline Entry & $\begin{array}{c}\text { BMNPs } \\
\text { (Mean Size, nm) }\end{array}$ & Structure & Metallic Precursors & $\begin{array}{l}\text { Synthetic } \\
\text { Procedure }\end{array}$ & Catalytic Reaction & Refs. \\
\hline 1 & $\mathrm{AuPd}(4-5)$ & core $(\mathrm{Au})$-shell( $(\mathrm{Pd})$ & $\mathrm{Au}(\mathrm{OAc})_{3}, \mathrm{Pd}(\mathrm{OAc})_{2}$ & co-reduction & $\begin{array}{l}\text { hydrogenations/ } \\
\text { hydrodehalogenations }\end{array}$ & [76] \\
\hline 2 & AuPd $(4.6 ; 3.2)$ & n.r. & $\mathrm{H}[\mathrm{AuCl}]_{4} \mathrm{~K}_{2}\left[\mathrm{PdCl}_{4}\right]$ & co-reduction & hydrogenations & [77-79] \\
\hline 3 & PtSn (2-3) & alloy & $\begin{array}{l}\mathrm{PtCl}_{2}, \mathrm{SnCl}_{2} \text { or } \\
\mathrm{Sn}(\mathrm{OAc})_{2}\end{array}$ & co-reduction & hydrogenations & [85] \\
\hline 4 & $\mathrm{RuCu}(2-3)$ & core $(\mathrm{Ru})$-shell $(\mathrm{Cu})$ & {$[\mathrm{Ru}(\mathrm{cod})(\mathrm{cot})][\mathrm{CuMes}]$} & co-reduction & hydrogenations & [86] \\
\hline 5 & FeRu (1.65) & n.r. & {$\left[\mathrm{Ru}_{3}(\mathrm{CO})_{12}\right]\left[\mathrm{Fe}_{2}(\mathrm{CO})_{9}\right]$} & co-decomposition & hydrogenations & [87] \\
\hline 6 & CuZn (45-50) & alloy & $\begin{array}{l}\mathrm{Cu}(\mathrm{II}) \text { and } \mathrm{Zn}(\mathrm{II}) \\
\text { amidinates }\end{array}$ & co-reduction & methanol synthesis & [90] \\
\hline 7 & $\mathrm{NiGa}(7-29 ; 12-19)$ & alloy & $\begin{array}{l}\mathrm{Ni}\left(\mathrm{NO}_{3}\right)_{2} \cdot 6 \mathrm{H}_{2} \mathrm{O} \\
\mathrm{Cu}\left(\mathrm{NO}_{3}\right)_{2} \cdot 6 \mathrm{H}_{2} \mathrm{O}\end{array}$ & co-pyrolysis & hydrogenations & [91] \\
\hline 8 & AuPd (3.7) & n.r. & $\begin{array}{c}\mathrm{K}_{2}\left[\mathrm{PdCl}_{4}\right] \\
\mathrm{H}[\mathrm{AuCl}]_{4} \cdot 4 \mathrm{H}_{2} \mathrm{O}\end{array}$ & sequential-reduction & oxidations & [42] \\
\hline
\end{tabular}

\section{Supercritical Fluids}

Supercritical fluid reactive deposition (SFRD), also called chemical fluid deposition (CFD), represents a robust and highly tunable method for the preparation of well-defined metallic nanoscale structures on solid supports, by the hydrogenation of appropriate metal salts or organometallic precursors from their solutions in supercritical conditions. The supercritical state of matter provides the combination of gas-like effusion and liquid-like solvent properties. Thus, the resulting high phase homogeneity due to intrinsically enhanced transport, brings forth an outstanding means to control both seeding and particle growth processes [110].

In particular, the synthesis of nanocatalysts on solid supports under supercritical fluid reactive deposition represents a novel methodology for the preparation of tailored nanoscale structures of a smaller size than using conventional impregnation methods. Thus, small bimetallic NPs $(<10 \mathrm{~nm})$ are of great interest due to their peculiar physical properties and reactivity profiles towards novel applications in catalysis. This enhanced control of morphology at the nanoscale arising from the high phase homogeneity under supercritical conditions (namely, enhanced gas-like effusion and liquid-like solvent properties) provides the means towards a new generation of catalysts of higher performance, yielding ultimately outstanding means towards enabling new reactivity pathways that would not otherwise be achievable [111].

\subsection{Synthesis of BMNPs in Supercritical Fluids}

Supercritical $\mathrm{CO}_{2}\left(\mathrm{scCO}_{2}\right)$ has been widely used due to the fact that it is cheap, non-toxic, non-flammable, and its high solubilizing properties have been exploited for metal precursors. Furthermore, the relatively low critical temperature $\left(\mathrm{Tc}=31^{\circ} \mathrm{C}\right)$ and pressure of $\mathrm{scCO}_{2}(\mathrm{pc}=73.8 \mathrm{bar})$, make its handling straightforward, employing standard high pressure technology [110]. Seminal contributions for the preparation of bimetallic NPs by this approach pioneered by the groups of Erkey [111-115] and Wai [116,117], opened new opportunities towards the preparation of tailored nanomaterials with high potential in catalysis by the impregnation of the solutes into finely organized architectures. In particular, this synthetic methodology consists of three main steps: dissolution of a metal complex in a supercritical fluid, followed by its sorption or adsorption onto a support, and its final transformation to a zero-valent metal species [111]. Taking advantage of the tunable characteristics of $\mathrm{scCO}_{2}$ displaying both solvent and anti-solvent properties, many nanostructured systems such as supported and unsupported NPs, quantum dots, nanofilms, nanorods, nanofoams, and nanowires can be produced without requiring additional purification or drying steps [113].

Supported bimetallic Au-Ag NPs on different substrates have been prepared by the SFRD of dimethyl(acetylacetonate)gold(III) and (1,5-cyclooctadiene)(hexafluoroacetylacetonato)silver(I) from 
supercritical $\mathrm{CO}_{2}$. The mean particle size varied between 4 and $28 \mathrm{~nm}$ depending on the support used (mean particle size on BP2000 $<\gamma-\mathrm{Al}_{2} \mathrm{O}_{3}<\mathrm{TiO}_{2}<\beta-\mathrm{CD}$; $\mathrm{BP}=$ Black Pearls; $\mathrm{CD}=$ cyclodextrin), as characterized by TEM (Figure 7). Notably, EDX analysis of single particles showed both monometallic and bimetallic Au-Ag core/shell NPs featuring a gold core covered by an intermetallic shell made of $\mathrm{Ag}_{1} \mathrm{Au}_{3}[118]$.
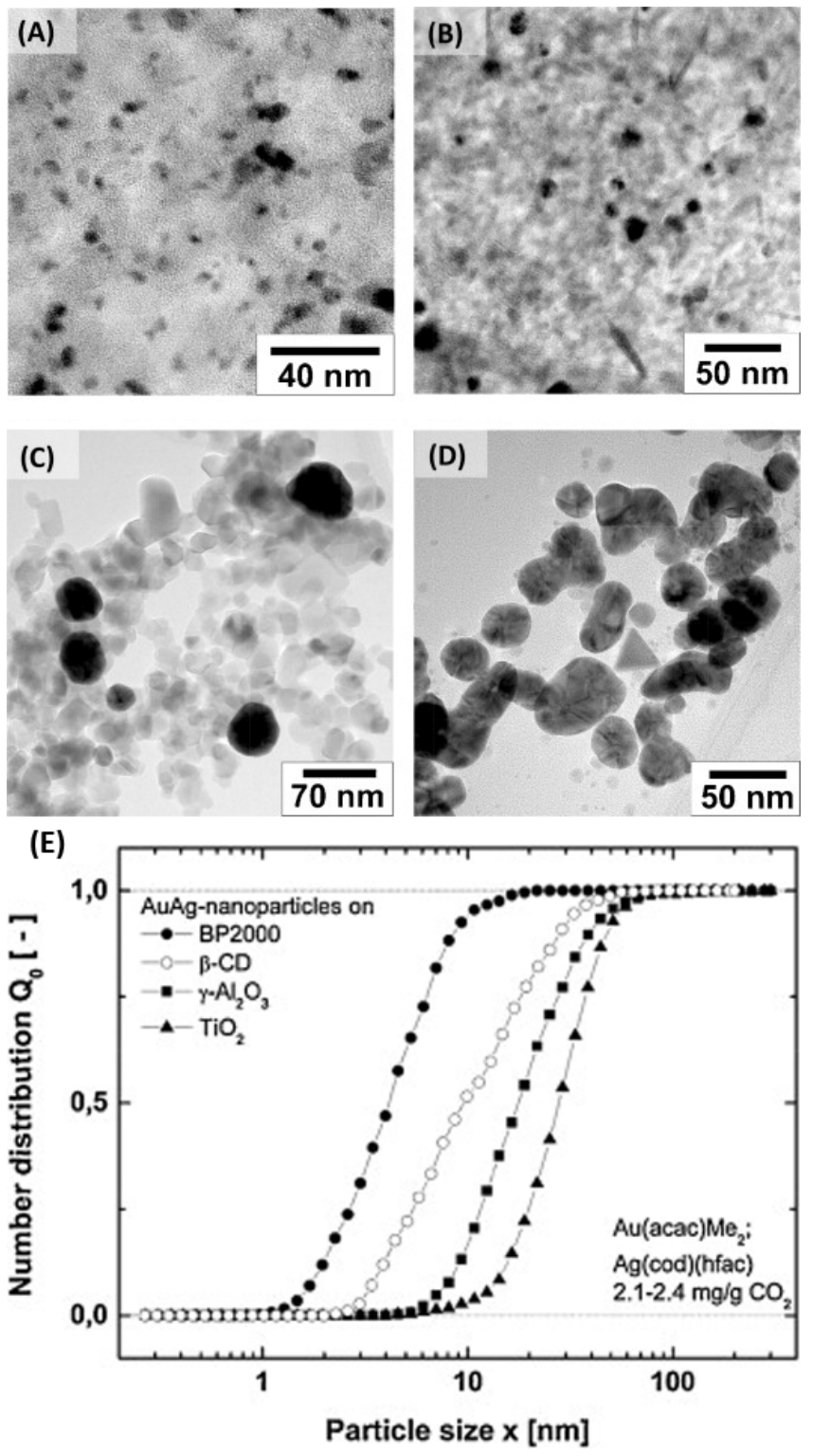

Figure 7. TEM images from Au-Ag NPs deposited on BP2000 (A), $\gamma-\mathrm{Al}_{2} \mathrm{O}_{3}(\mathbf{B}), \mathrm{TiO}_{2}(\mathbf{C})$, and $\beta-\mathrm{CD}$ (D) by SFRD at $353 \mathrm{~K}$ and $15.5 \mathrm{MPa}$, (E) particle size distribution of Au-Ag NPs deposited on BP2000, $\gamma-\mathrm{Al}_{2} \mathrm{O}_{3}, \mathrm{TiO}_{2}$, and $\beta-\mathrm{CD}$ by SFRD at $80{ }^{\circ} \mathrm{C}$ and 155 bar $\mathrm{CO}_{2}$. Reprinted with permission from reference [118]; license number 4126980392468. Copyright 2017, Elsevier.

Erkey et al., have described a supercritical deposition method to prepare aerogel-Cu nanocomposites. Thus, carbon, resorcinol-formaldehyde, and silica aerogels were impregnated with bis(1,1,1,3,5,5,6,6,6-nonafluorohexane-2,4-diiminate)copper (CuDI6), exhibiting high solubility in $\mathrm{scCO}_{2}$. Adsorbed $\mathrm{CuDI} 6$ was reduced to $\mathrm{Cu}$ and $\mathrm{Cu} / \mathrm{Cu}_{2} \mathrm{O}$ NPs on aerogel supports after thermal treatment (temperatures ranging from 200 to $400{ }^{\circ} \mathrm{C}$ ) or chemical reaction at ambient pressure [112] (Figure 8). Thus, $\mathrm{Cu}-\mathrm{Cu}_{2} \mathrm{O}$ core-shell nanoparticles could be obtained via a post-adsorption chemical 
conversion process using $\mathrm{H}_{2}$ at $250{ }^{\circ} \mathrm{C}$. NPs supported on resorcinol-formaldehyde aerogels also exhibited a core-shell arrangement with smaller sizes $(\sim 10 \mathrm{~nm})$ when compared to the NPs on carbon aerogels $(\sim 20-30 \mathrm{~nm})$; however, silica aerogels-supported nanoparticles were found in the form of "partial" core-shells. $\mathrm{Cu}-\mathrm{Cu}_{2} \mathrm{O}$ core-shell nanoparticles were synthesized when the carbon aerogel-CuDI6 composites were treated with $\mathrm{H}_{2}$ at $250{ }^{\circ} \mathrm{C}$, while phase segregated $\mathrm{Cu}-\mathrm{Cu}_{2} \mathrm{O}$ nanoparticles were obtained when an $\mathrm{O}_{2}$ treatment at $160{ }^{\circ} \mathrm{C}$ preceded the $\mathrm{H}_{2}$ treatment at $300{ }^{\circ} \mathrm{C}$ [112].
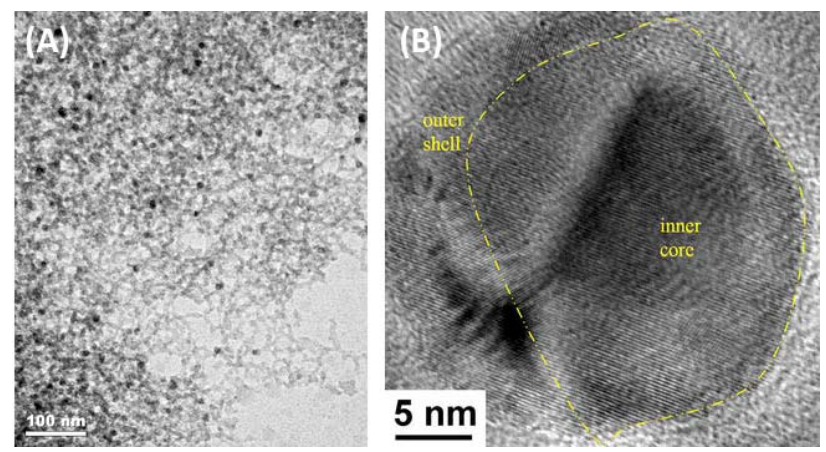

Figure 8. (A) TEM image of resorcinol-formaldehyde aerogel-supported $\mathrm{Cu}$ core- $\mathrm{Cu}_{2} \mathrm{O}$ shell nanoparticles prepared using chemical conversion in $\mathrm{H}_{2}$ after the adsorption from $\mathrm{scCO}_{2}$. (B) High magnification TEM image of a silica aerogel-supported partial core-shell nanoparticle prepared using chemical conversion in $\mathrm{H}_{2}$ after adsorption from $\mathrm{scCO}_{2}$. Reprinted with permission from reference [112]; license number 4127080686584. Copyright 2017, Springer.

Later reports from Erkey et al. describe the preparation of carbon aerogel supported Pt-Cu BMNPs via the simultaneous adsorption of the polyfluorinated copper precursor CuDI6 and dimethyl(1,5-cyclooctadiene)platinum(II) onto carbon aerogels in $\mathrm{scCO}_{2}$, followed by thermal conversion at ambient pressure [114]. Homogeneously dispersed Pt-Cu NPs were formed at the carbon aerogel surface through thermal decomposition of the precursors at $400{ }^{\circ} \mathrm{C}$. The metal $(\mathrm{Pt} / \mathrm{Cu})$ ratio could be easily controlled in the as-prepared materials, ranging from 97:3 to 21:79, which prompted an increase of both the mean diameter and the standard deviation of the particles, from 2.9-7.2 nm, and 1.3-3.7 nm, respectively (Figure 9). The alloying disposition of $\mathrm{Pt}$ and $\mathrm{Cu}$ atoms within the NPs was confirmed by means of XRD and XPS, indicating that the surfaces of these bimetallic Pt-Cu NPs were enriched in Pt [114].

Leventis et al. have also reported the synthesis of homogeneous Au-Ag bimetallic alloys in silica aerogels using a standard base-catalyzed route for the preparation of the silica aquogels which were initially prepared, washed several times, and then immersed in an aqueous solution of the metal ions (up to $3 \times 10^{-4} \mathrm{M}$ total metal ion concentration). As a reducing agent, formaldehyde $(0.5 \mathrm{M})$ was then added with $\mathrm{NaOH}(1-2 \mathrm{mM})$ as an additive. Next, the gels were washed again and then dried with $\mathrm{scCO}_{2}$ to yield the corresponding homogeneously alloyed Au-Ag BMNPs in silica aerogels, as confirmed by the linear shift to higher wavelengths of the single plasmon peak exhibited by their optical absorption upon an increase of the Au mole ratio [119]. TEM analysis showed that the diameter of the metal NPs depends on the molar ratio of the metal precursors used in the aquogel solution, ranging from $\sim 20 \mathrm{~nm}(100 \%$ Au sample) to $80 \mathrm{~nm}(25 \% \mathrm{Au})$; EDX analysis confirmed that the NPs are bimetallic [119]. 

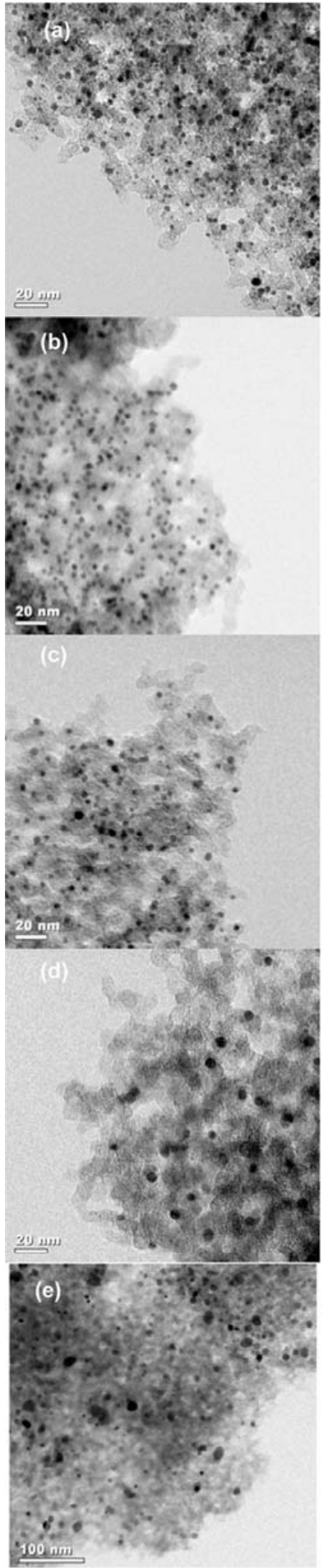
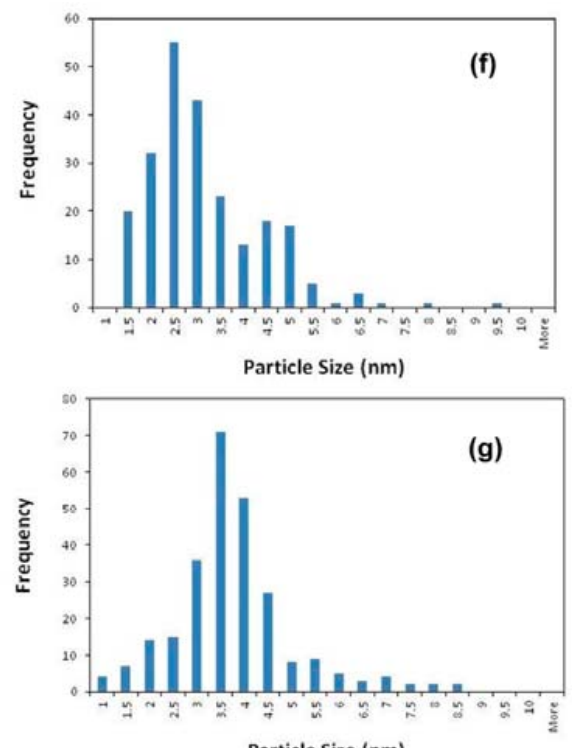

Particle Size $(\mathrm{nm})$

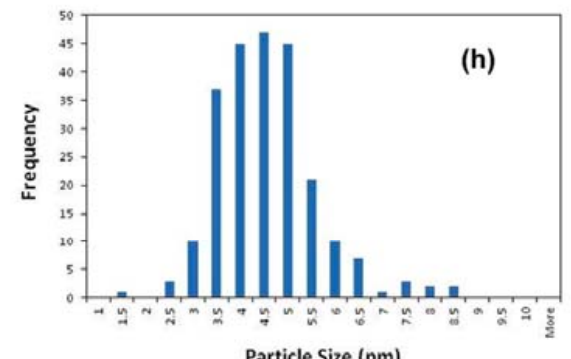

Particle Size (nm)
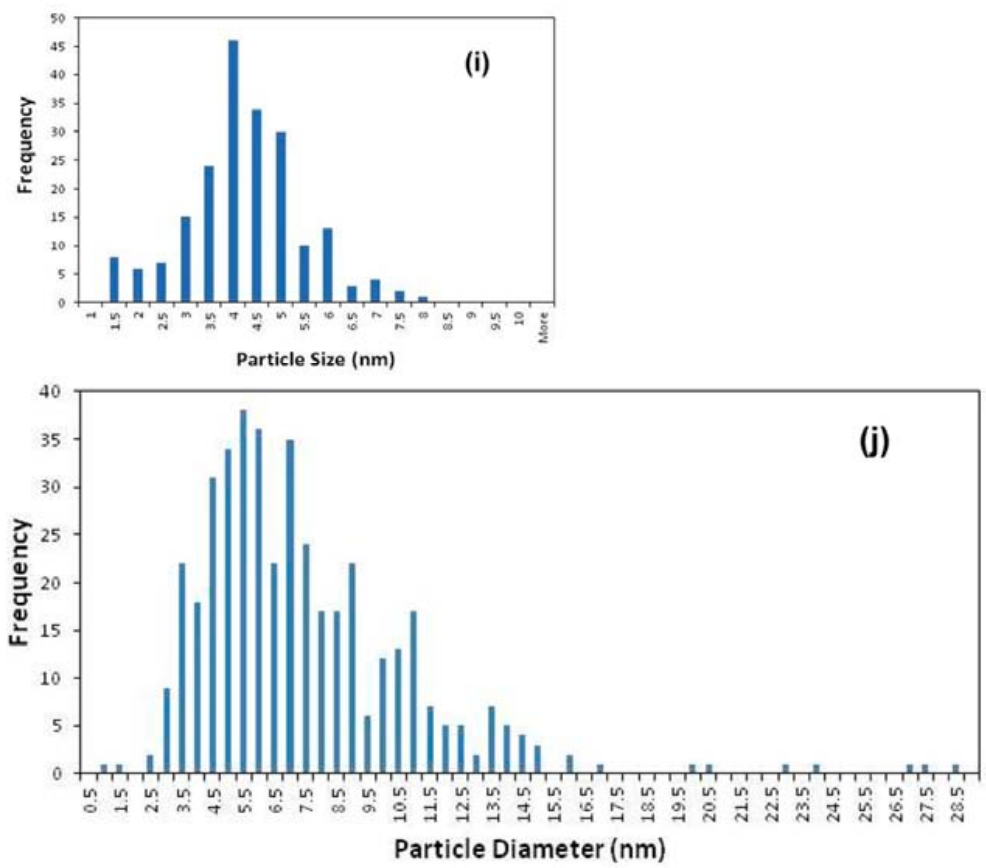

Figure 9. TEM images and particle size distributions of carbon aerogel supported Pt-Cu BMNPs prepared via the simultaneous adsorption of $\mathrm{Pt}$ and $\mathrm{Cu}$ complexes followed by thermal treatment at $400{ }^{\circ} \mathrm{C}$ and under atmospheric pressure: Pt/Cu mol ratio from XPS (a) 95:5; (b) 86:14; (c) 74:26; (d) 72:28; (e) 25:75; and (f-j) particle size distributions corresponding to materials (a-e), respectively. Reprinted with permission from reference [114]. Copyright 2017, American Chemical Society. 
Moreover, a couple of synthetic methods for the preparation of Pd-Pt NPs using $\mathrm{scCO}_{2}$ deposition have recently been reported. Thus far, Erkey et al. described their preparation from the simultaneous adsorption and subsequent reduction of palladium (II) acetylacetonate and dimethyl(cyclooctadiene)platinum (II) precursors on carbon black support (BP 2000) in $\mathrm{scCO}_{2}$ at $200 \mathrm{bar}$ and $60^{\circ} \mathrm{C}$ [115]. This methodology rendered a heterogeneous mixture of the BMNPs where Pt-rich NPs exhibited diameters of $\sim 4 \mathrm{~nm}$ and Pd-rich NPs appeared with larger diameters $(\sim 10 \mathrm{~nm})$, according to X-ray spectrometry analysis [115]. Besides, Srinivasan et al. described the preparation of Pd-Pt NPs within a dendrimer film matrix immobilized on a solid support by covalent molecular assembly using $\mathrm{scCO}_{2}$. The size, particle distribution, and composition could be controlled by choosing the best precursors and optimized conditions for Pd-Pt BMNPs. This methodology was later extended to the synthesis of Fe-Ni BMNPs, which exhibited relevant tribological properties [120].

Hexane modified $\mathrm{H}_{2} \mathrm{O}$-in- $\mathrm{CO}_{2}$ microemulsion. The $\mathrm{CO}_{2}$-based microemulsion process to deposit metal NPs on MWCNTs at room temperature has been described by Wai et al. [116]. In this method, metallic NPs are initially synthesized by $\mathrm{H}_{2}$ reduction of the metal ions dissolved in the water drops of a $\mathrm{H}_{2} \mathrm{O}$-in- $\mathrm{CO}_{2}$ microemulsion (sodium bis(2-ethylhexyl)sulfosuccinate used as a stabilizer) in a liquid $\mathrm{CO}_{2}$-hexane mixture, and then, MWCNTs are impregnated with the microemulsion solution containing metal nanoparticles. The metal salt precursor mixtures were efficiently deposited as BMNPs on the MWCNT surfaces, and the resulting particle diameters were in the $2-10 \mathrm{~nm}$ range. The as-synthesized MWCNT-supported Pd-Rh BMNPs showed great potential towards the hydrogenation of arenes and were reused without a loss of catalytic activity [116].

Supercritical MeOH (scMeOH). Protic solvents such as $\mathrm{MeOH}$ can also be used in supercritical conditions for the synthesis of noble metal nanostructures, due to their high solubilizing properties of metal precursors, such as $\mathrm{H}_{2}\left[\mathrm{PtCl}_{6}\right], \mathrm{H}\left[\mathrm{AuCl}_{4}\right]$, and $\mathrm{RuCl}_{3}$, and the ability to reduce them.

$\mathrm{Du}$ et al. have reported a simple and efficient route to deposit noble Pt-Ru and Ru-Sn BMNPs onto carbon nanotubes (CNTs) in scMeOH at $300^{\circ} \mathrm{C}$ for $30 \mathrm{~min}$, where $\mathrm{MeOH}$ acted as both the solvent and reductant of metal precursors. Mixtures of $\mathrm{H}_{2}\left[\mathrm{PtCl}_{6}\right] \cdot 6 \mathrm{H}_{2} \mathrm{O}$ and $\mathrm{RuCl}_{3} \cdot 3 \mathrm{H}_{2} \mathrm{O}$, and $\mathrm{RuCl}_{3} \cdot 3 \mathrm{H}_{2} \mathrm{O}$ and $\mathrm{SnCl}_{2} \cdot 2 \mathrm{H}_{2} \mathrm{O}$ were used as precursors, respectively. The as-prepared nanocomposites were decorated by crystalline metal nanoparticles with uniform sizes $(2-3 \mathrm{~nm})$ and a small particle size distribution, as concluded from TEM analyses [121].

\subsection{Applications in Catalysis of BMNPs in Supercritical Fluids}

Applications in the catalysis of highly performant catalytic systems in supercritical conditions offer new alternative means to tackle current challenges for the development of sustainable industrial processes based on green chemistry applications.

For instance, the current multi-ton requirements of propylene oxide as a monomer for the industrial production of polyurethane foams, resins, and propylene glycol, represent a fundamental subject of research and development in catalysis. Despite the most straightforward production process for propylene oxide synthesis, which is the direct oxidation of propylene with $\mathrm{O}_{2}$, the major hurdles to obtain a highly pure monomer under safe and high yielding processes have precluded major industrial applications. Díaz, Corma et al. reported an elegant one-pot two-step process for direct propylene oxide production from propylene, $\mathrm{H}_{2}$, and $\mathrm{O}_{2}$ catalyzed by a bifunctional material ( $\left.\mathrm{Pd}(\mathrm{Au}) @ \mathrm{TS}-1\right)$ based on metallic NPs supported on nanocrystalline titanium silicalite (TS-1) zeolites [122]. The resulting metallic nanoparticles encompassed the in situ formation of $\mathrm{H}_{2} \mathrm{O}_{2}$ in a controlled fashion, which triggered propylene epoxidation catalyzed by the TS-1 nanocrystalline matrix support, working under safe supercritical $\mathrm{CO}_{2}$ conditions. These bifunctional catalysts showed high reusability and stability demonstrated through several catalytic cycles, yielding a more sustainable process for future industrial applications [122]. For a summary of BMNPs in supercritical fluids applied in catalysis, see Table 4 at the end of this section.

Fischer-Tropsch synthesis. The latest developments towards fine optimization of the Fischer-Tropsch process, an essential industrial process for synthesizing hydrocarbons from $\mathrm{CO}$ and $\mathrm{H}_{2}$, 
have also focused on the developments of structural controlled nanostructured catalysts, highlighting the potential of nanostructured materials to unravel the in situ dynamic reaction mechanism [123].

The synthesis of a well-defined $\mathrm{Fe}-\mathrm{Co} / \mathrm{SiO}_{2}$ catalyst with Fe-Co NPs smaller than $10 \mathrm{~nm}$ has been reported by Corrias, Paschina et al., under the high-temperature supercritical drying of alco gels, featuring Fe in a bcc crystal phase, while the active phase of Co exhibits an hcp/fcc structure [124,125]. These results correlate with research reports from analogous monometallic systems, where the advantage of using supercritical hydrocarbons as media precluded the deactivation of a $\mathrm{Co} / \mathrm{Al}_{2} \mathrm{O}_{3}$ catalyst [126]. Moreover, it was found that supercritical media in combination with a Co- $\mathrm{Ru} / \gamma-\mathrm{Al}_{2} \mathrm{O}_{3}$ catalyst (prepared by conventional impregnation), prompted a higher $\mathrm{CO}$ conversion with an increase in the selectivity towards long-chain hydrocarbon products in supercritical reaction media [127].

Gasification of phenol. On the other hand, the search for catalytic processes that can break down molecules showing structural complexity towards the synthesis of low molecular weight monomers, to by-pass the current dependence on contingent petroleum resources for industrial applications, is a growing societal need. In this context, the catalytic gasification of phenol in supercritical water represents a valuable alternative for sustainable development. Chen et al. have recently reported the convenience of bimetallic non-noble-metal catalysts ( $\mathrm{Ni}-\mathrm{Co}$ and $\mathrm{Ni}-\mathrm{Zn}$ ) supported on graphitized carbon black, for the high efficiency gasification of biomass in $\mathrm{scH}_{2} \mathrm{O}$ (prepared by polyol reduction) [62]. In particular, a nearly complete gasification of phenol was achieved at $450{ }^{\circ} \mathrm{C}$. XRD, $X P S$, and TEM characterization analyses of the prepared materials revealed the formation of Ni-Co and Ni-Zn alloy phases. Further optimization of these catalytic systems is required because NPs agglomeration was found to be one of the main causes of the catalyst deactivation, ruling out efficient catalyst recycling [62].

Oxidation via combustion processes. A green method of depositing Pt-based BMNPs (Ru-Pt, $\mathrm{Cu}-\mathrm{Pt}$, Au-Pt, Pd-Pt, and Ni-Pt) on MWCNTs in $\mathrm{scCO}_{2}$ from solutions of the corresponding metal precursors (based on acetylacetonate or hexafluoroacetylacetonate complexes) has been described by Wai et al. for direct methanol fuel cell applications [117]. These MWCNT-supported BMNPs presented average sizes ranging from 2.8 to $9.3 \mathrm{~nm}$. These supported systems were active in electrocatalysis for direct methanol fuel cells, exhibiting efficiencies to oxidize methanol to $\mathrm{CO}_{2}$ at least $60 \%$ better than the previously reported MWCNT-supported monometallic PtNPs [117].

Water-gas shift reaction (WGSR). This reaction encompasses the transformation of $\mathrm{CO}$ and $\mathrm{H}_{2} \mathrm{O}$ vapor to form $\mathrm{CO}_{2}$ and $\mathrm{H}_{2}$ and represents the standard industrial process for the synthesis of $\mathrm{H}_{2}$. West et al. reported a new generation of highly performant catalysts towards WGSR based on $\mathrm{Al}_{2} \mathrm{O}_{3}$-supported $\mathrm{Pt}-\mathrm{CeO}_{\mathrm{x}}$ catalysts via supercritical fluid deposition from the organometallic precursor platinum(II) acetylacetonate. These supported $\mathrm{Pt}_{-} \mathrm{CeO}_{\mathrm{x}}$ catalysts featured PtNPs encapsulated in crystalline ceria and showed higher activity and greater reaction rates per mass of Pt than most literature values for WGSR on analogous Pt-CeOx catalysts [128]. Overall, these results show the great promise of SFRD as scalable means towards high performance catalysts enabling an efficient utilization of precious metals for the production of commodity gases such as $\mathrm{H}_{2}$ [128].

Hydrogenation reactions. Nanocatalysts are particularly well suited for hydrogenation reactions due to the surface tunability in terms of size, shape, and composition, which has a direct impact on the overall reactivity properties of the catalytic materials. Among the different techniques employed to achieve metal deposition, SCFD represents one of the most versatile and promising methodologies to furnish a new generation of catalytic materials, exhibiting the highest catalytic activity achieved thus far.

Tan et al. have recently described a simple and green method for the deposition of BMNPs (Ru-Rh, Ru-Pd, and Rh-Pd) onto a mesoporous silica support (MCM-41) in $\mathrm{scCO}_{2}$ starting from the corresponding metal acetylacetonates precursors [129]. The as-prepared NPs presented average sizes ranging from 2 to $8 \mathrm{~nm}$, characterized by TEM, XRD, and EDX; they were applied in the hydrogenation of $p$-xylene at $50{ }^{\circ} \mathrm{C}$ and 35 bar $\mathrm{H}_{2}$ pressure, resulting in catalytic activity (TOF $\sim 1400 \mathrm{~h}^{-1}$ ) that was nearly eight times better than other analogous catalysts prepared by conventional impregnation methods [129]. It is worth mentioning that the $\mathrm{Rh}-\mathrm{Pd} / \mathrm{MCM}-41$ catalyst showed a clear synergistic 
effect since the catalytic activity of the bimetallic system was higher than that of the individual monometallic catalysts combined [129].

Gas-expanded solvents provide outstanding means towards size-selective fractionation on metal NPs by minimizing the polydispersity of the obtained nanomaterials, as described by the early reports of Roberts et al., where they exploited the highly tunable properties of $\mathrm{scCO}_{2}$ and organic solvent mixtures towards selectively size-separate mixtures of polydisperse NPs $(2-12 \mathrm{~nm})$ into monodisperse $2 \mathrm{~nm}$ fractions [130].

The four-fold reaction rate enhancement for the selective hydrogenation of cyclohexenone to cyclohexanone at $\mathrm{scCO}_{2}$ pressures up to 60 bar on Fe-Ru BMNPs (prepared by thermal decomposition), suspended in 1-butyl-3-methylimidazolium tetrafluoroborate ([BMIm] $\left.\left[\mathrm{BF}_{4}\right]\right)$ from 1.6 to $2.9 \mathrm{~nm}$ diameter size, has recently been reported by Baiker et al., $\left(>95 \%\right.$, TOF $\left.=\sim 300 \mathrm{~h}^{-1}\right)$ [87], precluding over the reduction of the carbonyl group which is otherwise observed in the absence of $\mathrm{scCO}_{2}$. Moreover, the peculiar properties of $\mathrm{scCO}_{2}$ permit new "solventless" approaches in green transition metal catalysis, due to its use as a non-toxic and convenient extraction medium; the catalyst was reused five times without a noticeable loss of activity [87].

SFRD in $\mathrm{scCO}_{2}$ was employed for the generation of bimetallic Pt-Pd NPs ( $5 \mathrm{~nm}$ mean diameter) on SBA-15 as a mesoporous support by Leitner et al. TEM, STEM, and EDX analyses revealed that the highly uniform alloy-type NPs were deposited inside the pores [110]. The obtained composite materials showed high activity towards the hydrogenation of levulinic acid and concomitant cyclisation towards $\gamma$-valerolactone, achieving high TOF and TON values with high selectivity (Scheme 10) [110]. Overall, the bimetallic Pt-Pd NPs displayed superior activity in comparison to either of the analogous monometallic NPs alone.

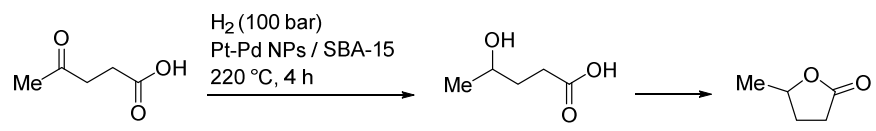

Scheme 10. Hydrogenation of levulinic acid to $\gamma$-valerolactone in aqueous solution catalyzed by bimetallic Pt-Pd NPs supported on SBA-15, achieving a nearly quantitative yield; total TON values up to 7200 and total TOF values up to $3600 \mathrm{~h}^{-1}$ [110].

Small bimetallic Pt-Ru NPs stabilized by 4-(3-phenylpropyl)pyridine and fluorinated phosphines (mean diameter 1.0-2.5 $\mathrm{nm}$ ) were prepared in $\mathrm{scCO}_{2}$ by Serp, Gómez et al., and these BMNPs exhibited a higher likelihood to be agglomerated in comparison with those BMNPs prepared in THF, but both types of BMNPs could be efficiently confined into functionalized multi-walled carbon nanotubes [131]. The as-prepared Pt-Ru/MWCNT catalytic materials were applied in cinnamaldehyde hydrogenation. Confined Pt-Ru NPs showed a significant higher selectivity and catalytic activity than unsupported NPs; reaction conditions were finely tuned to obtain a high selectivity towards the reduction of the aldehyde functional group. Thus, more than a $76 \%$ selectivity to the cinnamyl alcohol could be obtained, with 3-phenylpropanal and 3-phenylpropan-1-ol as the minor by-products (Scheme 11) [131].

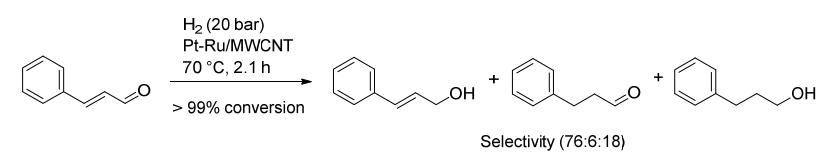

Scheme 11. Cinnamaldehyde hydrogenation catalyzed by confined nano-particles, Pt-Ru NPs into functionalized MWCNTs [131].

Micelle-hosted bimetallic Pd-Ru (1:1) NPs have been prepared by Tsang et al., via the in situ reduction of their salt precursors in $\mathrm{scCO}_{2}$ and used towards the catalytic hydrogenation of functionalized alkene under mild conditions. This highly performant catalytic system can be easily recycled without the need to use organic solvents [132]. 
Other more challenging hydrogenations of arenes have also been described with advanced bimetallic nanocatalysts. In particular, Tan et al. prepared Rh-Pt NPs with an average size of $\sim 6.1 \mathrm{~nm}$ on mesoporous silica SBA-15 (Rh-Pt/SBA-15) by CFD under $\mathrm{scCO}_{2}$, which showed a high performance towards the hydrogenation of terephthalic acid in water (full conversion was achieved at $80^{\circ} \mathrm{C}$ and 50 bar of $\mathrm{H}_{2}$ in $4 \mathrm{~h}$ ) (Scheme 12); clear cooperative effects were observed when compared to the corresponding parent monometallic catalysts (Rh/SBA-15 and Pt/SBA-15). The authors propose an enhanced absorption of arenes mediated by $\mathrm{Pt}$ on the active sites, whereas Rh plays a key role in the hydrogenation [133]. Other arenes such as bisphenol A, isophthalic acid, dimethyl phthalate, and benzoic acid were also efficiently reduced likewise.

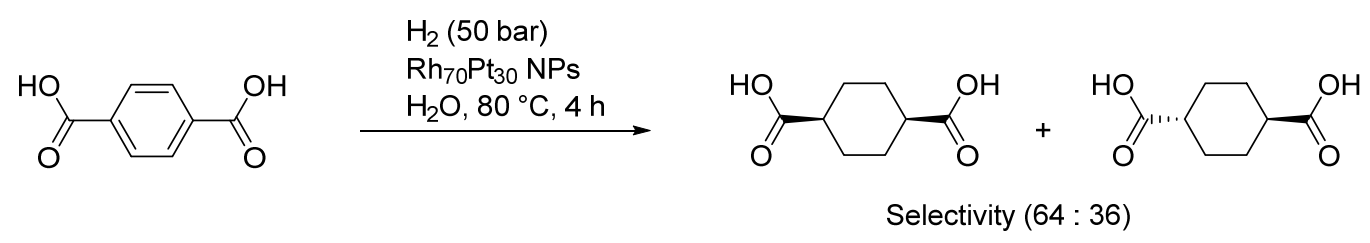

Scheme 12. Hydrogenation of terephthalic acid in water catalyzed by Rh-Pt BMNPs supported on mesoporous silica SBA-15 [133].

Furthermore, Zhang et al. have recently described highly performant colloidal bimetallic alloy nanocrystals that were applied not only in the hydrogenation of citral in $\mathrm{scCO}_{2}$, but also in C-C cross-coupling reactions such as Suzuki-Miyaura couplings [134]. The authors used a single-step strategy based on the direct thermal reduction of metal precursors in octadecylamine towards the preparation of octahedron- and rod-shaped metal aggregates of bimetallic alloy nanocrystals.

Suzuki cross-coupling reactions. Crooks et al. have prepared bimetallic and semiconductor nanoparticles by dendrimer-encapsulation (prepared by chemical reduction) [135]. The template effect of the dendrimers serves both to direct metal nucleation upon chemical reduction by affinity to the tertiary amine groups (PAMAM and PPI dendrimers) and to BMNP stabilization, yielding nearly size-monodisperse nanoparticular aggregates of less than $3 \mathrm{~nm}$ that can be further immobilized on inorganic oxide supports, such as silica and titania. Working under supercritical conditions with enhanced transport serves to overcome low turnover frequencies generally associated with this type of highly organized support, while conferring outstanding size-selectivity for the substrates [135]. To the best of our knowledge, the application of bimetallic dendrimer-encapsulated NPs in supercritical fluids remains to be explored.

Other types of biopolymeric materials have been successfully used for catalytic applications in supercritical fluids. In particular, Taran, Quignard et al. described the preparation of an easily recoverable hybrid catalyst via $\mathrm{scCO}_{2}$ drying, which combines the catalytic efficiency of PdNPs in a $\mathrm{Cu}^{2+}$ /alginate aerogel (Figure 10) [136]. This study evidences the dramatic effect of the gelling cation and highlights the synergetic effects between PdNPs and $\mathrm{Cu}^{2+}$ cations in the matrix, together with its high catalytic activity (TOF value of $10 \mathrm{~s}^{-1}$, and TON value close to 106), and the high robustness of the catalyst (no significant loss of activity or metal leaching could be detected) [136]. The as-prepared catalytic material was applied in Suzuki-Miyaura cross-coupling reactions between aryl bromides and aryl boronic acids, obtaining the corresponding cross-coupling products in moderate to excellent yields (47-99\%, 17 examples) [136]. 


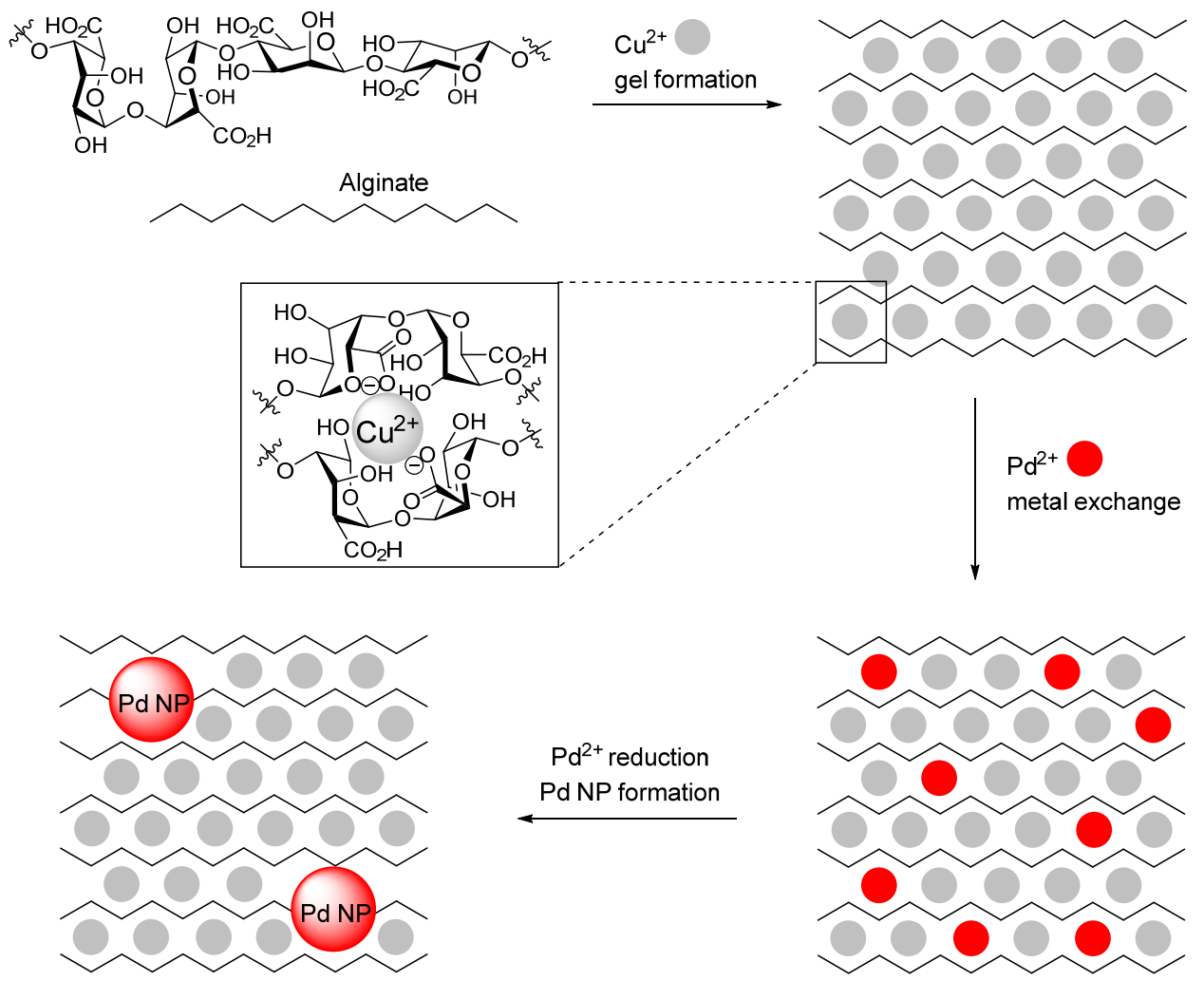

Figure 10. Chemical structure of alginate and schematic presentation of alginate $/ \mathrm{Cu}^{2+} / \mathrm{PdNPs}$ preparation [136].

Table 4. Bimetallic nanoparticles in $\mathrm{scCO}_{2}$ and $\mathrm{scH}_{2} \mathrm{O}$ applied in catalysis. ${ }^{\mathrm{a}}$

\begin{tabular}{|c|c|c|c|c|c|c|}
\hline Entry & $\begin{array}{c}\text { BMNPs } \\
\text { (Mean Size, nm) }\end{array}$ & Structure & Metallic Precursors & $\begin{array}{l}\text { Synthetic } \\
\text { Procedure }\end{array}$ & Catalytic Reaction & Refs. \\
\hline \multicolumn{7}{|c|}{$\mathrm{scCO}_{2}$} \\
\hline 2 & $\begin{array}{c}\mathrm{FeCo@SiO} 2 \\
(10-20)\end{array}$ & alloys (bcc) & $\begin{array}{l}\mathrm{Fe}\left(\mathrm{NO}_{3}\right)_{3} \cdot 9 \mathrm{H}_{2} \mathrm{O} \\
\mathrm{Co}\left(\mathrm{NO}_{3}\right)_{2} \cdot 6 \mathrm{H}_{2} \mathrm{O}\end{array}$ & co-reduction & Fischer-Tropsch & {$[124,125]$} \\
\hline 4 & $\begin{array}{c}\text { RuPt@ MWCNTs } \\
(2.0-3.6)\end{array}$ & $\begin{array}{l}\text { hcp and fcc } \\
\text { clusters }\end{array}$ & $\mathrm{Pt}(\mathrm{acac})_{2}, \mathrm{Ru}(\mathrm{acac})_{3}$ & co-reduction & combustion & [117] \\
\hline 5 & $\begin{array}{c}\text { CuPt@ MWCNTs } \\
(3.5-7.9)\end{array}$ & alloys (fcc) & $\mathrm{Pt}(\mathrm{acac})_{2}, \mathrm{Cu}(\mathrm{hfa})_{2}$ & co-reduction & combustion & [117] \\
\hline 6 & $\begin{array}{c}\text { AuPt@ MWCNTs } \\
(5.6-13)\end{array}$ & alloys (fcc) & $\mathrm{Pt}(\mathrm{acac})_{2}, \mathrm{AuMe}_{2}(\mathrm{acac})$ & co-reduction & combustion & [117] \\
\hline 8 & $\begin{array}{c}\text { NiPt@ MWCNTs } \\
(3.1-10.1)\end{array}$ & alloys (fcc) & $\mathrm{Pt}(\mathrm{acac})_{2}, \mathrm{Ni}(\mathrm{hfa})_{2}$ & co-reduction & combustion & [117] \\
\hline 9 & $\begin{array}{c}\mathrm{Pt}-\mathrm{CeO}_{\mathrm{x}} @ \mathrm{Al}_{2} \mathrm{O}_{3} \\
(2-4)\end{array}$ & $\begin{array}{l}\text { core }(\mathrm{Pt}) \text {-shell } \\
\left(\mathrm{CeO}_{\mathrm{x}}\right)\end{array}$ & $\mathrm{CeCl}_{3} \cdot 7 \mathrm{H}_{2} \mathrm{O}, \mathrm{Pt}(\mathrm{acac})_{2}$ & $\begin{array}{l}\text { calcination followed } \\
\text { by reduction }\end{array}$ & Water-gas shift & [128] \\
\hline 10 & $\begin{array}{c}\text { RuRh@MCM-41 } \\
(2.2-4.6)\end{array}$ & $\begin{array}{l}\text { hcp and fcc } \\
\text { clusters }\end{array}$ & $\operatorname{Ru}(\mathrm{acac})_{3}, \operatorname{Rh}(\mathrm{acac})_{3}$ & co-reduction & arene hydrogenations & [129] \\
\hline 11 & $\begin{array}{c}\text { RuPd@MCM-41 } \\
(2.3-3.5)\end{array}$ & $\begin{array}{l}\text { hcp and fcc } \\
\text { clusters }\end{array}$ & $\mathrm{Ru}(\mathrm{acac})_{3}, \operatorname{Pd}(\mathrm{acac})_{2}$ & co-reduction & arene hydrogenation & [129] \\
\hline 12 & $\begin{array}{l}\text { RhPd@MCM-41 } \\
(3.2-4.4)\end{array}$ & alloys & $\operatorname{Rh}(\mathrm{acac})_{3}, \operatorname{Pd}(\mathrm{acac})_{2}$ & co-reduction & arene hydrogenations & [129] \\
\hline
\end{tabular}


Table 4. Cont.

\begin{tabular}{|c|c|c|c|c|c|c|}
\hline Entry & $\begin{array}{c}\text { BMNPs } \\
\text { (Mean Size, nm) }\end{array}$ & Structure & Metallic Precursors & $\begin{array}{l}\text { Synthetic } \\
\text { Procedure }\end{array}$ & Catalytic Reaction & Refs. \\
\hline 14 & $\begin{array}{l}\text { PtPd@SBA-15 } \\
\quad(4.9-6.1)\end{array}$ & alloys & $\begin{array}{l}{\left[\mathrm{PtMe}_{2}(\mathrm{cod})\right]} \\
{[\mathrm{PdCp}(\text { allyl })]}\end{array}$ & co-reduction & ketone hydrogenation & [110] \\
\hline 15 & $\begin{array}{c}\text { PtRu@MWCNTs } \\
(1.0-2.5)\end{array}$ & alloys & $\begin{array}{l}{[\mathrm{Ru}(\mathrm{cod})(\mathrm{cot})]} \\
{\left[\mathrm{PtMe}_{2}(\mathrm{cod})\right]}\end{array}$ & co-reduction & $\begin{array}{l}\text { ketone and olefin } \\
\text { hydrogenations }\end{array}$ & [131] \\
\hline 16 & $\mathrm{PdRu}(3.5-4.4)$ & alloys & $\mathrm{Pd}\left(\mathrm{NO}_{3}\right)_{2}, \mathrm{RuCl}_{3}$ & co-reduction & olefin hydrogenations & [132] \\
\hline 18 & AuPd (7) & alloys & $\mathrm{PdCl}_{2}, \mathrm{H}\left[\mathrm{AuCl}_{4}\right] \cdot 4 \mathrm{H}_{2} \mathrm{O}$ & co-reduction & hydrogenatios & [134] \\
\hline 19 & $\mathrm{AuPt}(7)$ & alloys & $\begin{array}{l}\mathrm{H}_{2}\left[\mathrm{PtCl}_{6}\right] \cdot 6 \mathrm{H}_{2} \mathrm{O} \\
\mathrm{H}\left[\mathrm{AuCl}_{4}\right] \cdot 4 \mathrm{H}_{2} \mathrm{O}\end{array}$ & co-reduction & $\begin{array}{l}\text { Suzuki-Miyaura C-C } \\
\text { cross-couplings }\end{array}$ & [134] \\
\hline 20 & $\operatorname{PdPt}(1.5-2.3)$ & alloys & $\mathrm{K}_{2}\left[\mathrm{PdCl}_{4}\right], \mathrm{K}_{2}\left[\mathrm{PtCl}_{4}\right]$ & co-reduction & $\begin{array}{l}\text { Suzuki-Miyaura C-C } \\
\text { cross-couplings }\end{array}$ & [135] \\
\hline \multicolumn{7}{|c|}{$\mathrm{scH}_{2} \mathrm{O}$} \\
\hline 22 & 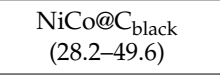 & alloys & $\begin{array}{l}\mathrm{Ni}\left(\mathrm{NO}_{3}\right)_{2} \cdot 6 \mathrm{H}_{2} \mathrm{O} \\
\mathrm{Co}\left(\mathrm{NO}_{3}\right)_{2} \cdot 6 \mathrm{H}_{2} \mathrm{O}\end{array}$ & co-reduction & gasification of phenol & {$[62]$} \\
\hline 23 & NiZn@C black (n.r.) & alloys & $\begin{array}{l}\mathrm{Ni}\left(\mathrm{NO}_{3}\right)_{2} \cdot 6 \mathrm{H}_{2} \mathrm{O} \\
\mathrm{Zn}\left(\mathrm{NO}_{3}\right)_{2} \cdot 6 \mathrm{H}_{2} \mathrm{O}\end{array}$ & co-reduction & gasification of phenol & {$[62]$} \\
\hline
\end{tabular}

\section{Outlook}

This review highlights the increasing use of non-conventional media (i.e., other than volatile organic compounds) in the synthesis of nanomaterials for catalytic purposes. Herein, we discuss the clear advantages of different solvents in the preparation of nanocatalysts, providing a templating effect for metal nanoparticle growth, as well as the possibility to control structural parameters such as size and morphology, which are crucial for the activity and selectivity of such catalytic processes. For bimetallic nanoparticles, the different arrangements (alloys, core-shell, heterodimers) can induce different electronic effects between the metal partners, besides the different nature of sites and the presence of stabilizers, which play an important role in terms of selectivity. With the aim of designing performant bimetallic nanocatalysts, cutting edge techniques for the structural elucidation and modelling of BMNPs, including the interaction with reagents, are required. As stated in the present review, the medium can tune the structure of BMNPs and also modify the catalytic pathways. Consequently, a thorough knowledge of the physico-chemical properties of innovative solvents is essential for gaining a precise control of the catalytic reactivity. Synthetic strategies, structural techniques, modelling, and solvent engineering need to be integrated together in the conception of any new synthetic process involving well-defined bimetallic nanoparticles in order to gain a better insight of the catalytic behavior, enabling the exploitation of their full potential towards synthetic applications.

Notably, the major enhancements obtained using supercritical fluids for the synthesis of a new generation of high performance catalytic materials require further exploration to unravel the full potential of techniques such as SFRD, where the combination of gas-like effusion and liquid-like solvent properties provide outstanding means towards the control of the morphology and dispersion of the nanomaterials through the fine tuning of seeding and particle growth processes. In particular, the number of scientific reports describing the use of $\mathrm{scCO}_{2}$ in combination with additives to further enhance the preparation of nanomaterials is still low. The use of (per)fluorinated compounds as additives for $\mathrm{scCO}_{2}$ show great promise and, in our opinion, this field will witness a rapid growth towards the elucidation of the best supercritical mixtures for the preparation of the next generation of nanocatalysts for sustainable catalytic applications needed to enable future developments. 
Nonetheless, the limitless possibilities arising from technological advancements of novel top-down physical techniques such as the laser sputtering of bulk metals towards enabling the preparation of well-defined polymetallic nanocomposites in combination with non-conventional media shall challenge current bottom-up synthetic protocols well beyond the redox potential limitations, and thus provide a means to prepare well-defined polymetallic systems.

Acknowledgments: Financial support from the Centre National de la Recherche Scientifique (CNRS) and the Université de Toulouse 3-Paul Sabatier are gratefully acknowledged. T.D.-B. thanks the Ministry of Education and Training of the Socialist Republic of Vietnam and CNRS for the PhD scholarship.

Conflicts of Interest: The authors declare no conflict of interest. The founding sponsors had no role in the design of the study; in the collection, analyses, or interpretation of data; in the writing of the manuscript, and in the decision to publish the results.

\section{References}

1. Schmid, G. (Ed.) Nanoparticles. From Theory to Application; Wiley-VCH: Weinheim, Germany, 2005.

2. Gao, W.; Hood, Z.D.; Chi, M. Interfaces in Heterogeneous Catalysts: Advancing Mechanistic Understanding through Atomic-Scale Measurements. Acc. Chem. Res. 2017, 50, 787-795. [CrossRef] [PubMed]

3. Ahmadi, M.; Mistry, H.; Roldan Cuenya, B. Tailoring the Catalytic Properties of Metal Nanoparticles via Support Interactions. J. Phys. Chem. Lett. 2016, 7, 3519-3533. [CrossRef] [PubMed]

4. Picos, A.; Riva, M.; Brambilla, A.; Calloni, A.; Bussetti, G.; Finazzi, M.; Ciccacci, F.; Duo, L. Reactive metal-oxide interfaces: A microscopic view. Surf. Sci. Rep. 2016, 71, 32-76. [CrossRef]

5. An, K.; Somorjai, G.A. Nanocatalysis I: Synthesis of Metal and Bimetallic Nanoparticles and Porous Oxides and Their Catalytic Reaction Studies. Catal. Lett. 2015, 145, 233-248. [CrossRef]

6. Navalon, S.; Dhakshinamoorthy, A.; Alvaro, M.; Garcia, H. Metal nanoparticles supported on two-dimensional graphenes as heterogeneous catalysts. Coord. Chem. Rev. 2016, 312, 99-148. [CrossRef]

7. Peng, L.; Ringe, E.; Van Duyne, R.P.; Marks, L.D. Segregation in bimetallic nanoparticles. Phys. Chem. Chem. Phys. 2015, 17, 27940-27951. [CrossRef] [PubMed]

8. Notar Francesco, I.; Fontaine-Vive, F.; Antoniotti, S. Synergy in the Catalytic Activity of Bimetallic Nanoparticles and New Synthetic Methods for the Preparation of Fine Chemicals. ChemCatChem. 2014, 6, 2784-2791. [CrossRef]

9. Tao, F.F. Synthesis, catalysis, surface chemistry and structure of bimetallic nanocatalysts. Chem. Soc. Rev. 2012, 41, 7977-7979. [CrossRef] [PubMed]

10. Liu, P.; Qin, R.; Fu, Q.; Zheng, N. Surface Coordination Chemistry of Metal Nanomaterials. J. Am. Chem. Soc. 2017, 139, 2122-2131. [CrossRef] [PubMed]

11. Zaleska-Medynska, A.; Marchelek, M.; Diak, M.; Grabowska, E. Noble metal-based bimetallic nanoparticles: The effect of the structure on the optical, catalytic and photocatalytic properties. Adv. Colloid Interface 2016, 229, 80-107. [CrossRef] [PubMed]

12. Chen, T.; Rodionov, V.O. Controllable Catalysis with Nanoparticles: Bimetallic Alloy Systems and Surface Adsorbates. ACS Catal. 2016, 6, 4025-4033. [CrossRef]

13. Gu, J.; Zhang, Y.-W.; Tao, F.F. Shape control of bimetallic nanocatalysts through well-designed colloidal chemistry approaches. Chem. Soc. Rev. 2012, 41, 8050-8065. [CrossRef] [PubMed]

14. Chen, Q.; Li, J.; Li, Y. A review of plasma-liquid interactions for nanomaterial synthesis. J. Phys. D Appl. Phys. 2015, 48, 424005-424031. [CrossRef]

15. Weiner, R.G.; Kunz, M.R.; Skrabalak, S.E. Seeding a New Kind of Garden: Synthesis of Architecturally Defined Multimetallic Nanostructures by Seed-Mediated Co-Reduction. Acc. Chem. Res. 2015, 48, 2688-2695. [CrossRef] [PubMed]

16. Shukla, A.K.; Iravami, S. Metallic nanoparticles: Green synthesis and spectroscopic characterization. Environ. Chem. Lett. 2017, 15, 223-231. [CrossRef]

17. De, S.; Dutta, S.; Sha, B. Critical design of heterogeneous catalysts for biomass valorization: Current thrust and emerging prospects. Catal. Sci. Technol. 2016, 6, 7364-7385. [CrossRef]

18. Kim, D.; Xie, C.; Becknell, N.; Yu, Y.; Karamad, M.; Chan, K.; Crumlin, E.J.; Nørskov, J.K.; Yang, P. Electrochemical Activation of $\mathrm{CO}_{2}$ through Atomic Ordering Transformations of Au-Cu Nanoparticles. J. Am. Chem. Soc. 2017. [CrossRef] [PubMed] 
19. Noël, S.; Léger, B.; Ponchel, A.; Philippot, K.; Denicourt-Nowicki, A.; Roucoux, A.; Monflier, E. Cyclodextrin-based systems for the stabilization of metallic $(0)$ nanoparticles and their versatile applications in catalysis. Catal. Today 2014, 235, 20-32. [CrossRef]

20. Denicourt-Nowicki, A.; Roucoux, A. Metallic nanoparticles in neat water for catalytic applications. In Nanomaterials in Catalysis; Serp, P., Philippot, K., Eds.; Wiley-VCH Verlag GmbH \& Co. KGaA: Weinheim, Germany, 2013; Chapter 2; pp. 55-95. [CrossRef]

21. Yang, J.; Lee, J.Y.; Ying, J.Y. Phase transfer and its applications in nanotechnology. Chem. Soc. Rev. 2011, 40, 1672-1696. [CrossRef] [PubMed]

22. Rai, R.K.; Gupta, K.; Behrens, S.; Li, J.; Xu, Q.; Singh, S.K. Highly active bimetallic nickel-palladium alloy nanoparticle catalyzed Suzuki-Miyaura reactions. ChemCatChem 2015, 7, 1806-1812. [CrossRef]

23. Gupta, K.; Rai, R.K.; Dwivedi, A.D.; Singh, S.K. Catalytic aerial oxidation of biomass-derived furans to furan carboxylic acids in water over bimetallic Ni-Pd alloy nanoparticle. ChemCatChem 2016, 8, 1-9. [CrossRef]

24. Rai, R.K.; Gupta, K.; Tyagi, D.; Mahata, A.; Behrens, S.; Yang, X.; Xu, Q.; Pathakad, B.; Singh, S.K. Access to highly active Ni-Pd bimetallic nanoparticle catalysts for C-C coupling reactions. Catal. Sci. Technol. 2016, 6, 5567-5579. [CrossRef]

25. Zhang, Q.; Wu, X.-P.; Zhao, G.; Li, Y.; Wang, C.; Liu, Y.; Gong, X.-Q.; Lu, Y. High-performance PdNi alloy structured in situ on monolithic metal foam for coalbed methane deoxygenation via catalytic combustion. Chem. Commun. 2015, 51, 12613-12616. [CrossRef] [PubMed]

26. Harikumar, K.R.; Ghosh, S.; Rao, C.N.R. X-ray Photoelectron Spectroscopic Investigations of Cu-Ni, Au-Ag, Ni-Pd, and Cu-Pd Bimetallic Clusters. J. Phys. Chem. A 1997, 101, 536-540. [CrossRef]

27. Zhu, N.-M.; Li, Y.; Zhang, F.-S. Catalytic dechlorination of polychlorinated biphenyls in subcritical water by Ni/Fe nanoparticles. Chem. Eng. J. 2011, 171, 919-925. [CrossRef]

28. Cervantes, F.J.; Rodríguez-López, J.L.; Peña-Martínez, M.; Ascacio-Valdes, J.A.; Aguilar, C.N.; Bahena, D. Enhanced Reduction of P-Nitrophenol by a Methanogenic Consortium Promoted by Metallic Nanoparticles. Water Air Soil Poll. 2016, 227, 368/1-368/9. [CrossRef]

29. Heshmatpour, F.; Abazari, R.; Balalaie, S. Preparation of monometallic (Pd, Ag) and bimetallic $(\mathrm{Pd} / \mathrm{Ag}$, $\mathrm{Pd} / \mathrm{Ni}, \mathrm{Pd} / \mathrm{Cu}$ ) nanoparticles via reversed micelles and their use in the Heck reaction. Tetrahedron 2012, 68, 3001-3011. [CrossRef]

30. Heshmatpour, F.; Abazari, R. Formation of dispersed palladium-nickel bimetallic nanoparticles in microemulsions: Synthesis, characterization, and their use as efficient heterogeneous recyclable catalysts for the amination reactions of aryl chlorides under mild conditions. RSC Adv. 2014, 4, 55815-55826. [CrossRef]

31. Singh, H.P.; Gupta, N.; Sharma, S.K.; Sharma, R.K. Synthesis of bimetallic Pt-Cu nanoparticles and their application in the reduction of rhodamine B. Colloids Sur. A 2013, 416, 43-50. [CrossRef]

32. Meena Kumari, M.; Jacob, J.; Philip, D. Green synthesis and applications of Au-Ag bimetallic nanoparticles. Spectrochim. Acta Part A 2015, 137, 185-192. [CrossRef] [PubMed]

33. Nasrollahzadeh, M.; Sajadi, S.M.; Rostami-Vartoonia, A.; Khalaj, M. Journey on greener pathways: Use of Euphorbia condylocarpa M. bieb as reductant and stabilizer for green synthesis of $\mathrm{Au} / \mathrm{Pd}$ bimetallic nanoparticles as reusable catalysts in the Suzuki and Heck coupling reactions in water. RSC Adv. 2014, 4, 43477-43484. [CrossRef]

34. Wang, C.-B.; Zhang, W.-X. Synthesizing Nanoscale Iron Particles for Rapid and Complete Dechlorination of TCE and PCBs. Environ. Sci. Technol. 1997, 31, 2154-2156. [CrossRef]

35. Nagpal, V.; Bokarea, A.D.; Chikate, R.C.; Rodec, C.V.; Paknikar, K.M. Reductive dechlorination of $\gamma$-hexachlorocyclohexane using Fe-Pd bimetallic nanoparticles. J. Hazard. Mater. 2010, 175, 680-687. [CrossRef] [PubMed]

36. Shiha, Y.-H.; Chena, M.-Y.; Su, Y.-F. Pentachlorophenol reduction by Pd/Fe bimetallic nanoparticles: Effects of copper, nickel, and ferric cations. Appl. Catal. B-Environ. 2011, 105, 24-29. [CrossRef]

37. Tee, Y.-H.; Bachas, L.; Bhattacharyya, D. Degradation of Trichloroethylene by Iron-Based Bimetallic Nanoparticles. J. Phys. Chem. C 2009, 113, 9454-9464. [CrossRef] [PubMed]

38. Zhang, Z.; Hu, S.; Baig, S.A.; Tang, J.; Xu, X. Catalytic dechlorination of Aroclor 1242 by Ni/Fe bimetallic nanoparticles. J. Colloid Interface Sci. 2012, 385, 160-165. [CrossRef] [PubMed]

39. Wang, X.; Lia, J.-R.; Fua, M.-L.; Yuanc, B.; Cuia, H.-J.; Wang, Y.-F. Fabrication and evaluation of Au-Pd core-shell nanocomposites for dechlorination of diclofenac in water. Environ. Technol. 2015, 36, 1510-1518. [CrossRef] [PubMed] 
40. Wang, L.; Yamauchi, Y. Strategic Synthesis of Trimetallic Au@Pd@Pt Core-Shell Nanoparticles from Poly(vinylpyrrolidone)-Based Aqueous Solution towards Highly Active Electrocatalysts. Chem. Mater. 2011, 23, 2457-2465. [CrossRef]

41. Balcha, T.; Strobl, J.R.; Fowler, C.; Dash, P.; Scott, R.W.J. Selective Aerobic Oxidation of Crotyl Alcohol Using AuPd Core-Shell Nanoparticles. ACS Catal. 2011, 1, 425-436. [CrossRef]

42. Maclennan, A.; Banerjee, A.; Scott, R.W.J. Aerobic oxidation of $\alpha, \beta$-unsaturated alcohols using sequentially-grown AuPd nanoparticles in water and tetraalkylphosphonium ionic liquids. Catal. Today 2013, 207, 170-179. [CrossRef]

43. Feng, F.; Ye, J.; Cheng, Z.; Xu, X.; Zhang, Q.; Ma, L.; Lu, C.; Li, X. Cu-Pd $/ \gamma-\mathrm{Al}_{2} \mathrm{O}_{3}$ catalyzed the coupling of multi-step reactions: Direct synthesis of benzimidazole derivatives. RSC Adv. 2016, 6, 72750-72755. [CrossRef]

44. Ge, Y.; Gao, T.; Wang, C.; Shah, Z.H.; Lu, R.; Zhang, S. Highly efficient silica coated CuNi bimetallic nanocatalyst from reverse microemulsion. J. Colloid Interface Sci. 2017, 491, 123-132. [CrossRef] [PubMed]

45. Kadu, B.S.; Hengne, A.M.; Biradar, N.S.; Rode, C.V.; Chikate, R.C. Reductive Cyclization of Levulinic Acid to $\gamma$-Valerolactone over Non-Noble Bimetallic Nanocomposite. Ind. Eng. Chem. Res. 2016, 55, 13032-13039. [CrossRef]

46. Darabdhara, G.; Boruah, P.K.; Borthakur, P.; Hussain, N.; Das, M.R.; Ahamad, T.; Alshehri, S.M.; Malgras, V.; Wu, K.C.-W.; Yamauchid, Y. Reduced graphene oxide nanosheets decorated with Au-Pd bimetallic alloy nanoparticles towards efficient photocatalytic degradation of phenolic compounds in water. Nanoscale 2016, 8, 8276-8287. [CrossRef] [PubMed]

47. Shi, J.; Long, C.; Li, A. Selective reduction of nitrate into nitrogen using Fe-Pd bimetallic nanoparticle supported on chelating resin at near-neutral pH. Chem. Eng. J. 2016, 286, 408-415. [CrossRef]

48. Ma, Y.; Wu, X.; Zhang, G. Core-shell Ag@Pt nanoparticles supported on sepiolite nanofibers for the catalytic reduction of nitrophenols in water: Enhanced catalytic performance and DFT study. Appl. Catal. B-Environ. 2017, 205, 262-270. [CrossRef]

49. Wang, X.; Wang, Y.-X.; Yuan, B.; Cuia, H.-J.; Fu, M.L. Fabrication of resin supported Au-Pd bimetallic nanoparticle composite to efficiently remove chloramphenicol from water. RSC Adv. 2015, 5, 18806-18812. [CrossRef]

50. Purushothaman, R.K.P.; Haveren, J.V.; Mayoral, A.; Melia'n-Cabrera, I.; Heeres, H.J. Exploratory Catalyst Screening Studies on the Base Free Conversion of Glycerol to Lactic Acid and Glyceric Acid in Water Using Bimetallic Au-Pt Nanoparticles on Acidic Zeolites. Top. Catal. 2014, 57, 1445-1453. [CrossRef]

51. Pryadchenko, V.V.; Srabionyan, V.V.; Kurzin, A.A.; Bulat, N.V.; Shemet, D.B.; Avakyan, L.A.; Belenov, S.V.; Volochaev, V.A.; Zizak, I.; Guterman, V.E.; et al. Bimetallic PtCu core-shell nanoparticles in PtCu/C electrocatalysts: Structural and electrochemical characterization. Appl. Catal. A-Gen. 2016, 525, 226-236. [CrossRef]

52. Fiévet, F.; Brayner, R. The Polyol Process. In Nanomaterials: A Danger or a Promise? Brayner, R., Fiévet, F., Coradin, T., Eds.; Springer: London, UK, 2013; Chapter 1; pp. 1-25. [CrossRef]

53. Biacchi, A.J.; Schaak, R.E. The Solvent Matters: Kinetic versus Thermodynamic Shape Control in the Polyol Synthesis of Rhodium Nanoparticles. ACS Nano 2011, 5, 8089-8099. [CrossRef] [PubMed]

54. Chadoura, F.; Pradel, C.; Gómez, M. Palladium Nanoparticles in Glycerol: A Versatile Catalytic System for C-X Bond Formation and Hydrogenation Process. Adv. Synth. Catal. 2013, 355, 3648-3660. [CrossRef]

55. Chadoura, F.; Pradel, C.; Gómez, M. Copper(I) Oxide Nanoparticles in Glycerol: A Convenient Catalyst for Cross-Coupling and Azide-Alkyne Cycloaddition Processes. ChemCatChem 2014, 6, 2929-2936. [CrossRef]

56. Reina, A.; Pradel, C.; Martin, E.; Teuma, E.; Gómez, M. Palladium nanoparticles stabilised by cinchona based alkaloids in glycerol: Efficient catalysts for surface assisted processes. RSC Adv. 2016, 6, 93205-93216. [CrossRef]

57. Dang-Bao, T.; Pradel, C.; Favier, I.; Gómez, M. Making Copper(0) Nanoparticles in Glycerol: A Straightforward Synthesis for a Multipurpose Catalyst. Adv. Synth. Catal. 2017. [CrossRef]

58. Biswas, M.; Saha, A.; Dule, M.; Mandal, T.K. Polymer-Assisted Chain-like Organization of CuNi Alloy Nanoparticles: Solvent-Adoptable Pseudohomogeneous Catalysts for Alkyne-Azide Click Reactions with Magnetic Recyclability. J. Phys. Chem. C 2014, 118, 22156-22165. [CrossRef] 
59. Rakap, M. Hydrogen generation from hydrolysis of ammonia borane in the presence of highly efficient poly( $N$-vinyl-2-pyrrolidone)-protected platinum-ruthenium nanoparticles. Appl. Catal. A-Gen. 2014, 478, 15-20. [CrossRef]

60. Vu, K.B.; Bukhryakov, K.V.; Anjum, D.H.; Rodionov, V.O. Surface-Bound Ligands Modulate Chemoselectivity and Activity of a Bimetallic Nanoparticle Catalyst. ACS Catal. 2015, 5, 2529-2533. [CrossRef]

61. Dabiri, M.; Vajargahy, M.P. PdCo bimetallic nanoparticles supported on three-dimensional graphene as a highly active catalyst for Sonogashira cross-coupling reaction. Appl. Organometal. Chem. 2017, $31,3594$. [CrossRef]

62. Jia, L.; Yu, J.; Chen, Y.; Ning, P.; Guan, Q.; Gu, J.; Miao, R.; Chen, Q. Noble-metal-free bimetallic alloy nanoparticle-catalytic gasification of phenol in supercritical water. J. Supercrit. Fluids 2017, 126, 79-88. [CrossRef]

63. Shen, Y.; Lua, A.C. Polyol synthesis of nickel-copper based catalysts for hydrogen production by methane decomposition. Int. J. Hydrogen Energy 2015, 40, 311-321. [CrossRef]

64. Shen, Y.; Lua, A.C. Synthesis of $\mathrm{Ni}$ and $\mathrm{Ni}-\mathrm{Cu}$ supported on carbon nanotubes for hydrogen and carbon production by catalytic decomposition of methane. Appl. Catal. B-Environ. 2015, 164, 61-69. [CrossRef]

65. Hallett, J.P.; Welton, T. Room-Temperature Ionic Liquids: Solvents for Synthesis and Catalysis. 2. Chem. Rev. 2011, 111, 3508-3576. [CrossRef] [PubMed]

66. Dupont, J. From Molten Salts to Ionic Liquids: A “Nano” Journey. Acc. Chem. Res. 2011, 44, $1223-1231$. [CrossRef] [PubMed]

67. Prechtl, M.H.G.; Campbell, P.S. Metal oxide and bimetallic nanoparticles in ionic liquids: Synthesis and application in multiphase catalysis. Nanotechnol. Rev. 2013, 2, 577-595. [CrossRef]

68. Scholten, J.D.; Leal, B.C.; Dupont, J. Transition Metal Nanoparticle Catalysis in Ionic Liquids. ACS Catal. 2012, 2, 184-200. [CrossRef]

69. Janiak, C. Metal Nanoparticle Synthesis in Ionic Liquids. Topics Organomet. Chem. 2015, 51, 17-53. [CrossRef]

70. Wegner, S.; Saito, M.; Barthel, J.; Janiak, C. Soft wet-chemical synthesis of Ru-Sn nanoparticles from single-source ruthenocene-stannole precursors in an ionic liquid. J. Organomet. Chem. 2016, 821, $192-196$. [CrossRef]

71. Suzuki, S.; Tomita, Y.; Kuwabata, S.; Torimoto, T. Synthesis of alloy AuCu nanoparticles with the L10 structure in an ionic liquid using sputter deposition. Dalton Trans. 2015, 44, 4186-4194. [CrossRef] [PubMed]

72. Helgadottir, I.S.; Arquilliere, P.P.; Brea, P.; Santini, C.C.; Haumesser, P.-H.; Richter, K.; Mudring, A.-V.; Aouine, M. Synthesis of bimetallic nanoparticles in ionic liquids: Chemical routes vs. physical vapor deposition. Microelectron. Eng. 2013, 107, 229-232. [CrossRef]

73. Pusch, J.M.E.; Brondani, D.; Luza, L.; Dupont, J.; Vieira, I.C. Pt-Pd bimetallic nanoparticles dispersed in an ionic liquid and peroxidase immobilized on nanoclay applied in the development of a biosensor. Analyst 2013, 138, 4898-4906. [CrossRef] [PubMed]

74. Tsai, T.-H.; Thiagarajan, S.; Chen, S.-M. Ionic liquid assisted one step green synthesis of Au-Ag bimetallic nanoparticles. J. Appl. Electrochem. 2010, 40, 493-497. [CrossRef]

75. Favier, I.; Teuma, E.; Gómez, M. Bimetallic Nanoparticles in Ionic Liquids: Synthesis and Catalytic Applications. In Nanocatalysis in Ionic Liquids; Prechtl, M.H.G., Ed.; John Wiley and Sons Ltd. Wiley-VCH Verlag GmbH: Hoboken, NJ, USA, 2016; Chapter 7; pp. 125-146.

76. Yuan, X.; Sun, G.; Asakura, H.; Tanaka, T.; Chen, X.; Yuan, Y.; Laurenczy, G.; Kou, Y.; Dyson, P.J.; Yan, N. Development of Palladium Surface-Enriched Heteronuclear Au-Pd Nanoparticle Dehalogenation Catalysts in an Ionic Liquid. Chem. Eur. J. 2013, 19, 1227-1234. [CrossRef] [PubMed]

77. Scott, R.W.J.; Dash, P. Bimetallic Nanoparticles as Catalysts in Imidazolium Ionic Liquids. In Ionic Liquids in Materials Synthesis and Application; Baker, G.A., Wilkes, J.S., Yang, H., Eds.; Materials Research Society Symposia Proceedings: Warrendale, PA, USA, 2008; Volume 1082.

78. Dash, P.; Dehm, N.A.; Scott, R.W.J. Bimetallic PdAu nanoparticles as hydrogenation catalysts in imidazolium ionic liquids. J. Mol. Catal. A Chem. 2008, 286, 114-119. [CrossRef]

79. Dash, P.; Miller, S.M.; Scott, R.W.J. Stabilizing nanoparticle catalysts in imidazolium-based ionic liquids: A comparative study. J. Mol. Catal. A Chem. 2010, 329, 86-95. [CrossRef]

80. Suzuki, S.; Suzuki, T.; Tomita, Y.; Hirano, M.; Okazaki, K.I.; Kuwabata, S.; Torimoto, T. Compositional control of AuPt nanoparticles synthesized in ionic liquids by the sputter deposition technique. CrystEngComm 2012, 14, 4922-4926. [CrossRef] 
81. Hirano, M.; Enokida, K.; Okazaki, K.I.; Kuwabata, S.; Yoshida, H.; Torimoto, T. Composition-dependent electrocatalytic activity of AuPd alloy nanoparticles prepared via simultaneous sputter deposition into an ionic liquid. Phys. Chem. Chem. Phys. 2013, 15, 7286-7294. [CrossRef] [PubMed]

82. Liu, C.H.; Liu, J.; Zhou, Y.Y.; Cai, X.L.; Lu, Y.; Gao, X.; Wang, S.D. Small and uniform Pd monometallic/bimetallic nanoparticles decorated on multi-walled carbon nanotubes for efficient reduction of 4-nitrophenol. Carbon 2015, 94, 295-300. [CrossRef]

83. Ding, K.; Liu, L.; Cao, Y.; Yan, X.; Wei, H.; Guo, Z. Formic acid oxidation reaction on a PdxNiy bimetallic nanoparticle catalyst prepared by a thermal decomposition process using ionic liquids as the solvent. Int. J. Hydrogen Energy 2014, 39, 7326-7337. [CrossRef]

84. Ding, K.; Yang, H.; Cao, Y.; Zheng, C.; Rapole, S.B.; Guo, Z. Using ionic liquid as the solvent to prepare Pd-Ni bimetallic nanoparticles by a pyrolysis method for ethanol oxidation reaction. Mater. Chem. Phys. 2013, 142, 403-411. [CrossRef]

85. Dietrich, C.; Schild, D.; Wang, W.; Kübel, C.; Behrens, S.Z. Bimetallic Pt/Sn-based Nanoparticles in Ionic Liquids as Nanocatalysts for the Selective Hydrogenation of Cinnamaldehyde. Z. Anorg. Allg. Chem. 2017, 643, 120-129. [CrossRef]

86. Arquillière, P.P.; Helgadottir, I.S.; Santini, C.C.; Haumesser, P.H.; Aouine, M.; Massin, L.; Rousset, J.L. Bimetallic Ru-Cu Nanoparticles Synthesized in Ionic Liquids: Kinetically Controlled Size and Structure. Top. Catal. 2013, 56, 1192-1198. [CrossRef]

87. Andanson, J.M.; Marx, S.; Baiker, A. Selective hydrogenation of cyclohexenone on iron-ruthenium nano-particles suspended in ionic liquids and $\mathrm{CO}_{2}$-expanded ionic liquids. Catal. Sci. Technol. 2012, 2, 1403-1409. [CrossRef]

88. Laurenczy, G.; Dyson, P.J. Determination of the Viscosity of the Ionic Liquids [bmim][PF6] and [bmim][TF2N] Under High $\mathrm{CO}_{2}$ Gas Pressure Using Sapphire NMR Tubes. Z. Naturforsch. B Chem. Sci. 2008, 63, 681-684. [CrossRef]

89. Solinas, M.; Pfaltz, A.; Cozzi, P.G.; Leitner, W. Enantioselective Hydrogenation of Imines in Ionic Liquid/Carbon Dioxide Media. J. Am. Chem. Soc. 2004, 126, 16142-16147. [CrossRef] [PubMed]

90. Schütte, K.; Meyer, H.; Gemel, C.; Barthel, J.; Fischer, R.A.; Janiak, C. Synthesis of Cu, Zn and Cu/Zn brass alloy nanoparticles from metal amidinate precursors in ionic liquids or propylene carbonate with relevance to methanol synthesis. Nanoscale 2014, 6, 3116-3126. [CrossRef] [PubMed]

91. Schütte, K.; Doddi, A.; Kroll, C.; Meyer, H.; Wiktor, C.; Gemel, C.; van Tendeloo, G.; Fischer, R.A.; Janiak, C. Colloidal nickel/gallium nanoalloys obtained from organometallic precursors in conventional organic solvents and in ionic liquids: Noble-metal-free alkyne semihydrogenation catalysts. Nanoscale 2014, 6, 5532-5544. [CrossRef] [PubMed]

92. Weilhard, A.; Abarca, G.; Viscardi, J.; Prechtl, M.H.G.; Scholten, J.D.; Bernardi, F.; Baptista, D.L.; Dupont, J. Challenging Thermodynamics: Hydrogenation of Benzene to 1,3-Cyclohexadiene by Ru@Pt Nanoparticles. ChemCatChem 2017, 9, 204-221. [CrossRef]

93. Chang, J.B.; Liu, C.H.; Liu, J.; Zhou, Y.Y.; Gao, X.; Wang, S.D. Green-chemistry Compatible Approach to $\mathrm{TiO}_{2}$-supported PdAu Bimetallic Nanoparticles for Solvent-free 1-Phenylethanol Oxidation under Mild Conditions. Nano-Micro Lett. 2015, 7, 307-315. [CrossRef]

94. Liu, C.H.; Chen, X.Q.; Hu, Y.F.; Sham, T.K.; Sun, Q.J.; Chang, J.B.; Gao, X.; Sun, X.H.; Wang, S.D. One-Pot Environmentally Friendly Approach toward Highly Catalytically Active Bimetal-Nanoparticle-Graphene Hybrids. ACS Appl. Mater. Interfaces 2013, 5, 5072-5079. [CrossRef] [PubMed]

95. Liu, C.H.; Liu, R.H.; Sun, Q.J.; Chang, J.B.; Gao, X.; Liu, Y.; Lee, S.T.; Kang, Z.H.; Wang, S.D. Controlled synthesis and synergistic effects of graphene-supported PdAu bimetallic nanoparticles with tunable catalytic properties. Nanoscale 2015, 7, 6356-6362. [CrossRef] [PubMed]

96. Alonso, D.A.; Baeza, A.; Chinchilla, R.; Guillena, G.; Pastor, I.M.; Ramon, D.J. Deep Eutectic Solvents: The Organic Reaction Medium of the Century. Eur. J. Org. Chem. 2016, 612-632. [CrossRef]

97. Dai, Y.; van Spronsen, J.; Witkamp, G.-J.; Verpoorte, R.; Choi, Y.H. Natural deep eutectic solvents as new potential media for green technology. Anal. Chim. Acta 2013, 766, 61-68. [CrossRef] [PubMed]

98. Liu, P.; Hao, J.-W.; Mo, L.-P.; Zhang, Z.-H. Recent advances in the application of deep eutectic solvents as sustainable media as well as catalysts in organic reactions. RSC Adv. 2015, 5, 48675-48704. [CrossRef]

99. Garcia-Alvarez, J. Deep Eutectic Mixtures: Promising Sustainable Solvents for Metal-Catalyzed and Metal-Mediated Organic Reactions. Eur. J. Inorg. Chem. 2015, 5147-5157. [CrossRef] 
100. Guajardo, N.; Mueller, C.R.; Schrebler, R.; Carlesi, C.; Dominguez de Maria, P. Deep Eutectic Solvents for Organocatalysis, Biotransformations, and Multistep Organocatalyst/Enzyme Combinations. ChemCatChem 2016, 8, 1020-1027. [CrossRef]

101. Wagle, D.V.; Zhao, H.; Baker, G.A. Deep Eutectic Solvents: Sustainable Media for Nanoscale and Functional Materials. Acc. Chem. Res. 2014, 47, 2299-2308. [CrossRef] [PubMed]

102. Abo-Hamad, A.; Hayyan, M.; AlSaadi, M.A.; Hashim, M.A. Potential applications of deep eutectic solvents in nanotechnology. Chem. Eng. J. 2015, 273, 551-567. [CrossRef]

103. Oseguera-Galindo, D.O.; Machorro-Mejia, R.; Bogdanchikova, N.; Mota-Morales, J.D. Silver nanoparticles synthesized by laser ablation confined in urea choline chloride deep-eutectic solvent. Colloid Interface Sci. Commun. 2016, 12, 1-4. [CrossRef]

104. Hammons, J.A.; Ustarroz, J.; Muselle, T.; Torriero, A.A.J.; Terryn, H.; Suthar, K.; Ilavsky, J. Supported Silver Nanoparticle and Near-Interface Solution Dynamics in a Deep Eutectic Solvent. J. Phys. Chem. C 2016, 120, 1534-1545. [CrossRef]

105. Raghuwanshi, V.S.; Ochmann, M.; Hoell, A.; Polzer, F.; Rademann, K. Deep Eutectic Solvents for the Self-Assembly of Gold Nanoparticles: A SAXS, UV-Vis, and TEM Investigation. Langmuir 2014, 30, 6038-6046. [CrossRef] [PubMed]

106. Karimi, M.; Eshraghi, M.J.; Jahangir, V. A facile and green synthetic approach based on deep eutectic solvents toward synthesis of CZTS nanoparticles. Mater. Lett. 2016, 171, 100-103. [CrossRef]

107. Renjith, A.; Lakshminarayanan, V. One step preparation of 'ready to use' Au@Pd nanoparticle modified surface using deep eutectic solvents and a study of its electrocatalytic properties in methanol oxidation reaction. J. Mater. Chem. A 2015, 3, 3019-3028. [CrossRef]

108. Wang, R.X.; Fan, Y.J.; Liang, Z.R.; Zhang, J.M.; Zhou, Z.Y.; Sun, S.G. PdSn nanocatalysts supported on carbon nanotubes synthesized in deep eutectic solvents with high activity for formic acid electrooxidation. RSC Adv. 2016, 6, 60400-60406. [CrossRef]

109. Gage, S.H.; Ruddy, D.A.; Pylypenko, S.; Richards, R.M. Deep eutectic solvent approach towards nickel/nickel nitride nanocomposites. Catal. Today 2016. [CrossRef]

110. Qiao, Y.; Said, N.; Rauser, M.; Yan, K.; Qin, F.; Theyssen, N.; Leitner, W. Preparation of SBA-15 supported $\mathrm{Pt} / \mathrm{Pd}$ bimetallic catalysts using supercritical fluid reactive deposition: How do solvent effects during material synthesis affect catalytic properties? Green Chem. 2017, 19, 977-986. [CrossRef]

111. Bozbag, S.E.; Erkey, C. Supercritical deposition: Current status and perspectives for the preparation of supported metal nanostructures. J. Supercrit. Fluids 2015, 96, 298-312. [CrossRef]

112. Bozbag, S.E.; Kostenko, S.O.; Kurykin, M.; Khrustalev, V.N.; Khokhlov, A.R.; Zhang, L.; Aindow, M.; Erkey, C. Aerogel-copper nanocomposites prepared using the adsorption of a polyfluorinated complex from supercritical $\mathrm{CO}_{2}$. J. Nanopart. Res. 2012, 14,973/1-973/13. [CrossRef]

113. Bozbag, S.E.; Sanli, D.; Erkey, C. Synthesis of nanostructured materials using supercritical $\mathrm{CO}_{2}$ : Part II. Chemical transformations. J. Mater. Sci. 2012, 47, 3469-3492. [CrossRef]

114. Bozbag, S.E.; Unal, U.; Kurykin, M.A.; Ayala, C.J.; Aindow, M.; Erkey, C. Thermodynamic Control of Metal Loading and Composition of Carbon Aerogel Supported Pt-Cu Alloy Nanoparticles by Supercritical Deposition. J. Phys. Chem. C 2013, 117, 6777-6787. [CrossRef]

115. Canguel, B.; Zhang, L.C.; Aindow, M.; Erkey, C. Preparation of carbon black supported Pd, Pt and Pd-Pt nanoparticles using supercritical $\mathrm{CO}_{2}$ deposition. J. Supercrit. Fluids 2009, 50, 82-90. [CrossRef]

116. Wang, J.S.; Pan, H.-B.; Wai, C.M. Deposition of metal nanoparticles on carbon nanotubes via hexane modified water-in- $\mathrm{CO}_{2}$ microemulsion at room temperature. J. Nanosci. Nanotechnol. 2006, 6, 2025-2030. [CrossRef] [PubMed]

117. Yen, C.H.; Shimizu, K.; Lin, Y.-Y.; Bailey, F.; Cheng, I.F.; Wai, C.M. Chemical Fluid Deposition of Pt-Based Bimetallic Nanoparticles on Multiwalled Carbon Nanotubes for Direct Methanol Fuel Cell Application. Energy Fuel. 2007, 21, 2268-2271. [CrossRef]

118. Mueller, S.; Tuerk, M. Production of supported gold and gold-silver nanoparticles by supercritical fluid reactive deposition: Effect of substrate properties. J. Supercrit. Fluids 2015, 96, 287-297. [CrossRef]

119. Hund, J.F.; Bertino, M.F.; Zhang, G.; Sotiriou-Leventis, C.; Leventis, N. Synthesis of homogeneous alloy metal nanoparticles in silica aerogels. J. Non-Cryst. Solids 2004, 350, 9-13. [CrossRef]

120. Puniredd, S.R.; Weiyi, S.; Srinivasan, M.P. Pd-Pt and Fe-Ni nanoparticles formed by covalent molecular assembly in supercritical carbon dioxide. J. Colloid Interface Sci. 2008, 320, 333-340. [CrossRef] [PubMed] 
121. Sun, Z.; Fu, L.; Liu, Z.; Han, B.; Liu, Y.; Du, J. Synthesis of noble metal/carbon nanotube composites in supercritical methanol. J. Nanosci. Nanotechnol. 2006, 6, 691-697. [CrossRef] [PubMed]

122. Prieto, A.; Palomino, M.; Díaz, U.; Corma, A. One-pot two-step process for direct propylene oxide production catalyzed by bi-functional Pd(Au)@TS-1 materials. Appl. Catal. A-Gen. 2016, 523, 73-84. [CrossRef]

123. Zhai, P.; Sun, G.; Zhu, Q.; Ma, D. Fischer-Tropsch synthesis nanostructured catalysts: Understanding structural characteristics and catalytic reaction. Nanotechnol. Rev. 2013, 2, 547-576. [CrossRef]

124. Casula, M.F.; Corrias, A.; Paschina, G. FeCo-SiO ${ }_{2}$ nanocomposite aerogels by high temperature supercritical drying. J. Mater. Chem. 2002, 12, 1505-1510. [CrossRef]

125. Corrias, A.; Casula, M.F.; Falqui, A.; Paschina, G. Preparation and characterization of $\mathrm{FeCo}-\mathrm{Al}_{2} \mathrm{O}_{3}$ and $\mathrm{Al} 2 \mathrm{O} 3$ aerogels. J. Sol-Gel Sci. Technol. 2004, 31, 83-86. [CrossRef]

126. Jacobs, G.; Chaudhari, K.; Sparks, D.; Zhang, Y.; Shi, B.; Spicer, R.; Das, T.K.; Li, J.; Davis, B.H. Fischer-Tropsch synthesis: Supercritical conversion by using a $\mathrm{Co} / \mathrm{Al}_{2} \mathrm{O}_{3}$ catalyst in a fixed bed reactor. Fuel 2003, 82, 1251-1260. [CrossRef]

127. Irankhah, A.; Haghtalab, A. Fischer-Tropsch synthesis over $\mathrm{Co}-\mathrm{Ru} / \gamma-\mathrm{Al}_{2} \mathrm{O}_{3}$ catalyst in supercritical media. Chem. Eng. Technol. 2008, 31, 525-536. [CrossRef]

128. Deal, J.W.; Le, P.; Corey, C.B.; More, K.; West, C.W. Water-gas shift reaction on alumina-supported Pt-CeOx catalysts prepared by supercritical fluid deposition. J. Supercrit. Fluids 2017, 119, 113-121. [CrossRef]

129. Yen, C.H.; Lin, H.W.; Phan, T.D.; Tan, C.-S. Chemical fluid deposition of monometallic and bimetallic nanoparticles on ordered mesoporous silica as hydrogenation catalysts. J. Nanosci. Nanotechnol. 2011, 11, 2465-2469. [CrossRef] [PubMed]

130. Anand, M.; McLeod, M.C.; Bell, P.W.; Roberts, C.B. Tunable solvation effects on the size-selective fractionation of metal NPs in $\mathrm{CO}_{2}$ gas-expanded solvents. J. Phys. Chem. B 2005, 109, 22852-22859. [CrossRef] [PubMed]

131. Castillejos, E.; Jahjah, M.; Favier, I.; Orejón, A.; Pradel, C.; Teuma, E.; Masdeu-Bultó, A.M.; Serp, P.; Gómez, M. Synthesis of Platinum-Ruthenium Nanoparticles under Supercritical $\mathrm{CO}_{2}$ and their Confinement in Carbon Nanotubes: Hydrogenation Applications. ChemCatChem 2012, 4, 118-122. [CrossRef]

132. Yu, K.M.K.; Meric, P.; Tsang, S.C. Micelle-hosted bimetallic Pd-Ru nanoparticle for in situ catalytic hydrogenation in supercritical $\mathrm{CO}_{2}$. Catal. Today 2006, 114, 428-433. [CrossRef]

133. Yu, W.; Hsu, Y.-P.; Tan, C.-S. Synthesis of rhodium-platinum bimetallic catalysts supported on SBA-15 by chemical fluid deposition for the hydrogenation of terephthalic acid in water. Appl. Catal. B-Environ. 2016, 196, 185-192. [CrossRef]

134. Song, S.; Liu, R.; Zhang, Y.; Feng, J.; Liu, D.; Xing, Y.; Zhao, F.; Zhang, H. Colloidal Noble-Metal and Bimetallic Alloy Nanocrystals: A General Synthetic Method and Their Catalytic Hydrogenation Properties. Chem. Eur. J. 2010, 16, 6251-6256. [CrossRef] [PubMed]

135. Scott, R.W.J.; Wilson, O.M.; Crooks, R.M. Synthesis, Characterization, and Applications of Dendrimer-Encapsulated Nanoparticles. J. Phys. Chem. B 2005, 109, 692-704. [CrossRef] [PubMed]

136. Chtchigrovsky, M.; Lin, Y.; Ouchaou, K.; Chaumontet, M.; Robitzer, M.; Quignard, F.; Taran, F. Dramatic Effect of the Gelling Cation on the Catalytic Performances of Alginate-Supported Palladium Nanoparticles for the Suzuki-Miyaura Reaction. Chem. Mater. 2012, 24, 1505-1510. [CrossRef]

(C) 2017 by the authors. Licensee MDPI, Basel, Switzerland. This article is an open access article distributed under the terms and conditions of the Creative Commons Attribution (CC BY) license (http://creativecommons.org/licenses/by/4.0/). 